\title{
A systematic review of the effects of psychiatric medications on social cognition
}

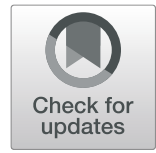

Zoë Haime ${ }^{1 *} \mathbb{D}$, Andrew J. Watson ${ }^{2}$, Nadia Crellin ${ }^{1}$, Louise Marston ${ }^{3}$, Eileen Joyce ${ }^{2}$ and Joanna Moncrieff ${ }^{1}$

\begin{abstract}
Introduction: Social cognition is an important area of mental functioning relevant to psychiatric disorders and social functioning, that may be affected by psychiatric drug treatments. The aim of this review was to investigate the effects of medications with sedative properties, on social cognition.

Method: This systematic review included experimental and neuroimaging studies investigating drug effects on social cognition. Data quality was assessed using a modified Downs and Black checklist (Trac et al. CMAJ 188: E120$E 129,2016)$. The review used narrative synthesis to analyse the data.

Results: 40 papers were identified for inclusion, 11 papers investigating benzodiazepine effects, and 29 investigating antipsychotic effects, on social cognition.

Narrative synthesis showed that diazepam impairs healthy volunteer's emotion recognition, with supporting neuroimaging studies showing benzodiazepines attenuate amygdala activity. Studies of antipsychotic effects on social cognition gave variable results. However, many of these studies were in patients already taking medication, and potential practice effects were identified due to short-term follow-ups.

Conclusion: Healthy volunteer studies suggest that diazepam reduces emotional processing ability. The effects of benzodiazepines on other aspects of social cognition, as well as the effects of antipsychotics, remain unclear. Interpretations of the papers in this review were limited by variability in measures, small sample sizes, and lack of randomisation. More robust studies are necessary to evaluate the impact of these medications on social cognition.
\end{abstract}

Keywords: Social cognition, Psychopharmacology, Schizophrenia, Antipsychotic, Benzodiazepine

\section{Introduction (narrative synthesis element 1: theory development) \\ What is social Cognition?}

Social cognition is defined as the mental processes which underlie the ability to understand and act on the thoughts, intentions, and behaviours of others [1]. Deficits in social cognition have been found in psychiatric disorders including depression, schizophrenia and

\footnotetext{
* Correspondence: z.haime@ucl.ac.uk

${ }^{1}$ Psychiatry Department, University College London, London, UK

Full list of author information is available at the end of the article
}

bipolar disorder [2-4] and can lead to the faulty interpretation of others' intentions and thinking, as well as inaccuracies in identifying others' emotions [5].

Social cognition can be separated into individual testable domains. However, many of these domains overlap, and there is no consistent agreement between cognitive scientists as to which are the most important. In psychiatry research the domains most frequently studied tend to reflect those identified by the National Institute of Mental Health (NIMH) at their meeting to define social

(C) The Author(s). 2021 Open Access This article is licensed under a Creative Commons Attribution 4.0 International License, which permits use, sharing, adaptation, distribution and reproduction in any medium or format, as long as you give appropriate credit to the original author(s) and the source, provide a link to the Creative Commons licence, and indicate if changes were made. The images or other third party material in this article are included in the article's Creative Commons licence, unless indicated otherwise in a credit line to the material. If material is not included in the article's Creative Commons licence and your intended use is not permitted by statutory regulation or exceeds the permitted use, you will need to obtain permission directly from the copyright holder. To view a copy of this licence, visit http://creativecommons.org/licenses/by/4.0/ The Creative Commons Public Domain Dedication waiver (http://creativecommons.org/publicdomain/zero/1.0/) applies to the data made available in this article, unless otherwise stated in a credit line to the data. 
cognition in schizophrenia in 2006 [6, 7]. These domains can be seen in Fig. 1, and include: Theory of mind (ToM) - the ability to 'infer intentions, dispositions, and beliefs of others' [8]; emotion processing - the ability to perceive emotions and interpret them appropriately [9]; social perception - the ability to process social cues and context to decipher social situations [10]; attributional bias - how people interpret the causes of events, which may be positive or negative in nature [11]; and social knowledge - how mental schemas of social situations guide behaviour [12]. Additional domains of social cognition tested in research include emotional intelligence, prejudice and stereotyping, and empathy [6].

Social functioning deficits are a core feature of most psychiatric diagnoses and considered an integral treatment target for many conditions, in order to promote recovery $[13,14]$. Social cognition deficits have been associated with poor social functioning in several psychiatric disorders including schizophrenia, bipolar disorder, anorexia, Alzheimer's disorder, and depression [2, 3, 1517]. Additionally, in schizophrenia better social cognitive ability has been linked to better social functioning outcomes [18]. This makes social cognition a potential target for treatment interventions across psychiatric care.

\section{Psychiatric medications}

The existing studies showing social cognition deficits in psychiatric disorders often involve people who are currently taking psychiatric medication [19]. However, it is unclear how these medications might affect social cognition. Many psychiatric medications have sedative effects, including benzodiazepines, antipsychotics (to varying degrees) and drugs used as mood stabilisers (22), and evidence suggests these drugs impair neurocognitive functioning in volunteers [20-23]. Antipsychotics also impair cognitive functioning in people with Alzheimer's disease [24], but evidence on the effects of antipsychotics in people diagnosed with schizophrenia is inconclusive. Some evidence suggests that antipsychotics improve neurocognitive functioning $[25,26]$ and some that they impair it $[27,28]$.

Along with sedative effects, psychiatric medications affect emotion and motivation. Antipsychotics, for example, reduce motivation and suppress emotions in volunteers [29], effects which are also reported by patients [30], and these effects may impact on social cognition. On the other hand, psychiatric drugs may improve social cognition by alleviating symptoms that impair social interaction, such as psychotic symptoms and anxiety.

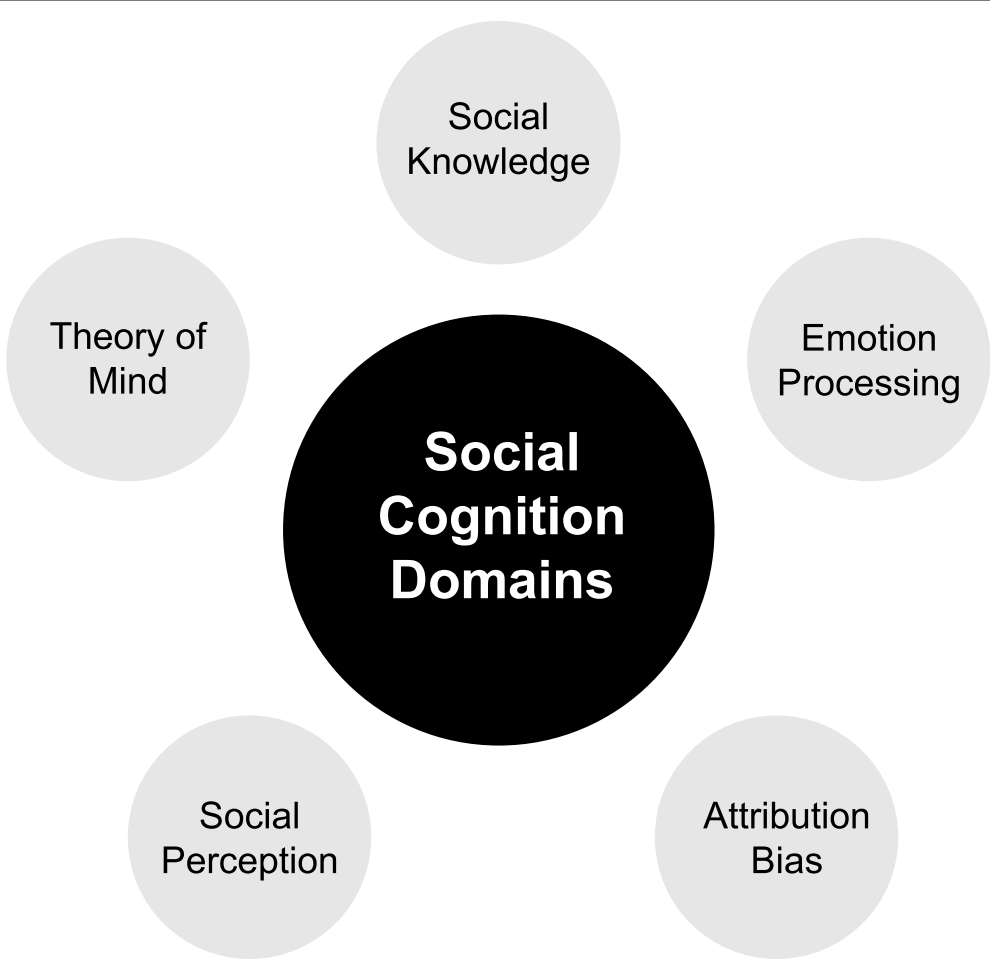

Fig. 1 Social Cognition Domains identified by the NIMH 
Moreover, different agents within the same class may have different effects on social cognition, depending on their sedative profile and other effects [31].

Therefore, there is good reason to believe that psychiatric medications may influence social cognition, especially those with sedative actions that are known to impair neurocognitive functioning in volunteers. Clarifying these effects is important in order to understand the nature of social cognitive deficits in psychiatric disorders, and to evaluate the effects of treatment on social cognition and associated outcomes, such as social functioning. A previous review highlighted the paucity of evidence on the effects of antipsychotic treatment, but it did not explore the use of other medications or effects in volunteers [31]. Volunteer studies help to distinguish those effects that occur in the absence of symptoms of psychiatric disorders from those that are related to the disorder itself, or to the interaction of the treatment with the disorder. They can help with the interpretation of studies with patients who are taking medication, and ultimately improve our understanding of this complex area.

\section{Neuroimaging}

The realisation that social disability may be linked to cognitive dysfunction has led to the employment of neuroimaging techniques to study this phenomenon in psychiatric populations, including the use of electroencephalography (EEG) and functional magnetic resonance imaging (fMRI). EEG can identify temporal changes in brain activity in response to specific tasks via event-related potentials (ERP), and fMRI is used to detect the location of changes in brain activity via variations in blood-oxygen-level-dependence (BOLD) [32, 33]. ERPs typically associated with social cognitive emotional stimuli are the P300-P400 potentials, where the brain shows activations $300-400 \mathrm{~ms}$ post-stimulus [34]. In fMRI, a social cognitive brain network has been identified and includes consistent activation of regions, including the temporo-parietal junction (TPJ), anterior cingulate cortex (ACC), superior temporal sulcus (STS), ventral and dorsal medial prefrontal cortex (VMPFC and DMPFC), precuneus, and inferior frontal gyrus (IFG) [35]. Neuroimaging studies investigating the effects of sedative medications on social cognition will help to identify any temporal or spatial neural changes in social cognitive brain regions, as a result of medication effects. This research is important in allowing researchers to assess the biological impact of psychiatric pharmaceutical treatments. In studies where patients have been using psychiatric medications with sedative effects long-term, permanent changes to structural and functional brain systems may inhibit the identification of medication effects on social cognition, Therefore, healthy volunteer and drug-naïve patient studies will be integral to our understanding of medication effects on social cognition in neuroimaging studies.

\section{Aims}

Despite evidence of effects on neurocognitive functioning, there has been little consideration of how psychiatric medications affect social cognition. We hypothesised that psychiatric medications that produce sedative effects might affect social cognition, and we conducted a systematic review of the literature in this area. We included research on healthy volunteers as well as research conducted with patients with diagnosed psychiatric disorders.

An additional aim of this review was to explore any temporal or spatial brain differences between healthy volunteers and clinical populations with psychiatric diagnoses conducting social cognition tasks after administration of psychiatric medication using neuroimaging technology. Notable differences in brain activity may reflect the effects of medication on social cognitive processing.

The review will help to clarify the nature of any underlying deficits in social cognition in people diagnosed with psychiatric disorders, and this will help in the development of targeted treatments for social cognition, which may also improve social functioning and general outcomes [28].

\section{Method \\ Protocol and registration}

This review follows the PRISMA guidelines for reporting systematic reviews [36]. The review protocol is available on the PROSPERO registry, ID: CRD42018092883.

\section{Narrative synthesis}

The scope of our narrative synthesis was to examine the effects of sedative medications on social cognition. Following guidance from Popay et al. [37] we used four iterative elements shown in Fig. 2. As the first point suggests, we conducted an initial scoping of the literature to summarise the current research in the field, and in order to construct our search strategy. To address point two, we reported our findings in the results section and summarised relevant data from the included papers in a table (Table 1). In our discussion we critically explored relationships between the reported studies and went on to discuss the strengths and limitations of the current review, to address points three and four. 


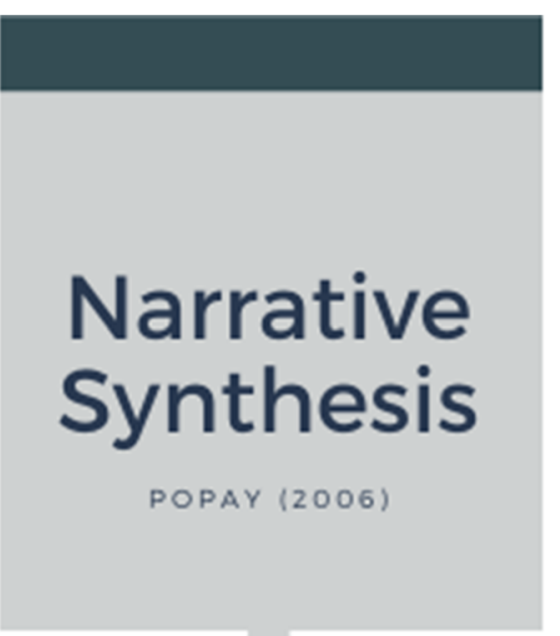

- THEORY

DEVELOPMEN T

2

- PRELIMINARY SYNTHESIS O F F IN D IN G S

3

- exploRATION OF STUDY RELATION SHIPS

- ASSESSMENT OF

4 SYNTHESIS ROBUSTNESS

Fig. 2 The four iterative elements of narrative synthesis [37]

\section{Search strategy}

We searched the following major databases: MEDLINE (OViD), Embase, Psychinfo, Web of Science, Lilacs, and Scopus as well as grey literature through greylit.org and opengrey.eu. Database-specific search terms included the keywords 'social cognition', 'mental disorder', 'neuroleptic agents', 'sedatives', and 'tranquilisers' with intervention-specific terms (including names of drug classes, and individual agents in classes that were not included as a whole, e.g., some sedative antidepressants), diagnosis-specific terms, outcomespecific subtypes and synonyms (see Additional file 1: Appendix A for full list of search terms and search strategy). An attempt to find additional studies was made through a backward reference search and contacting experts in the field. 


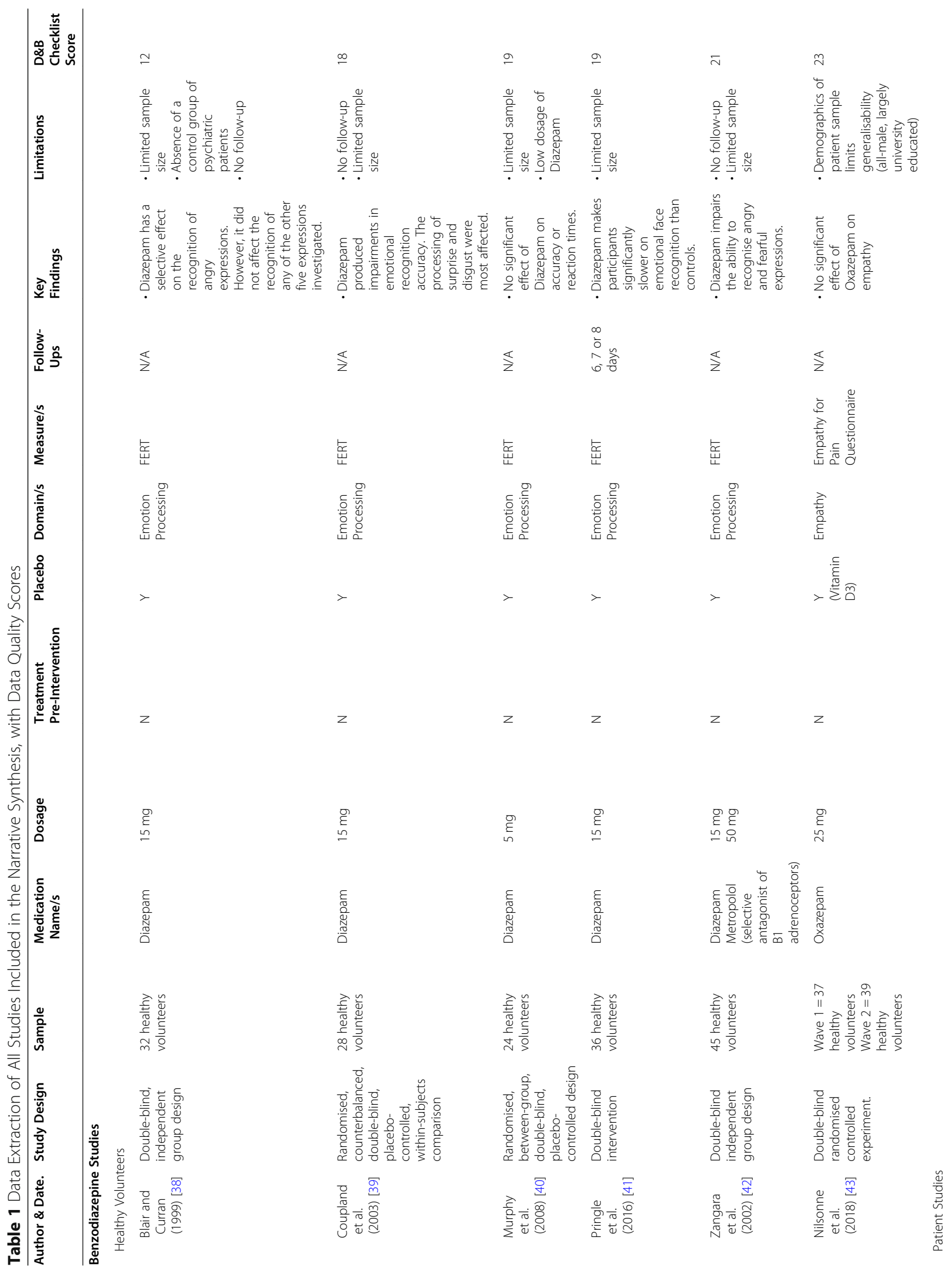




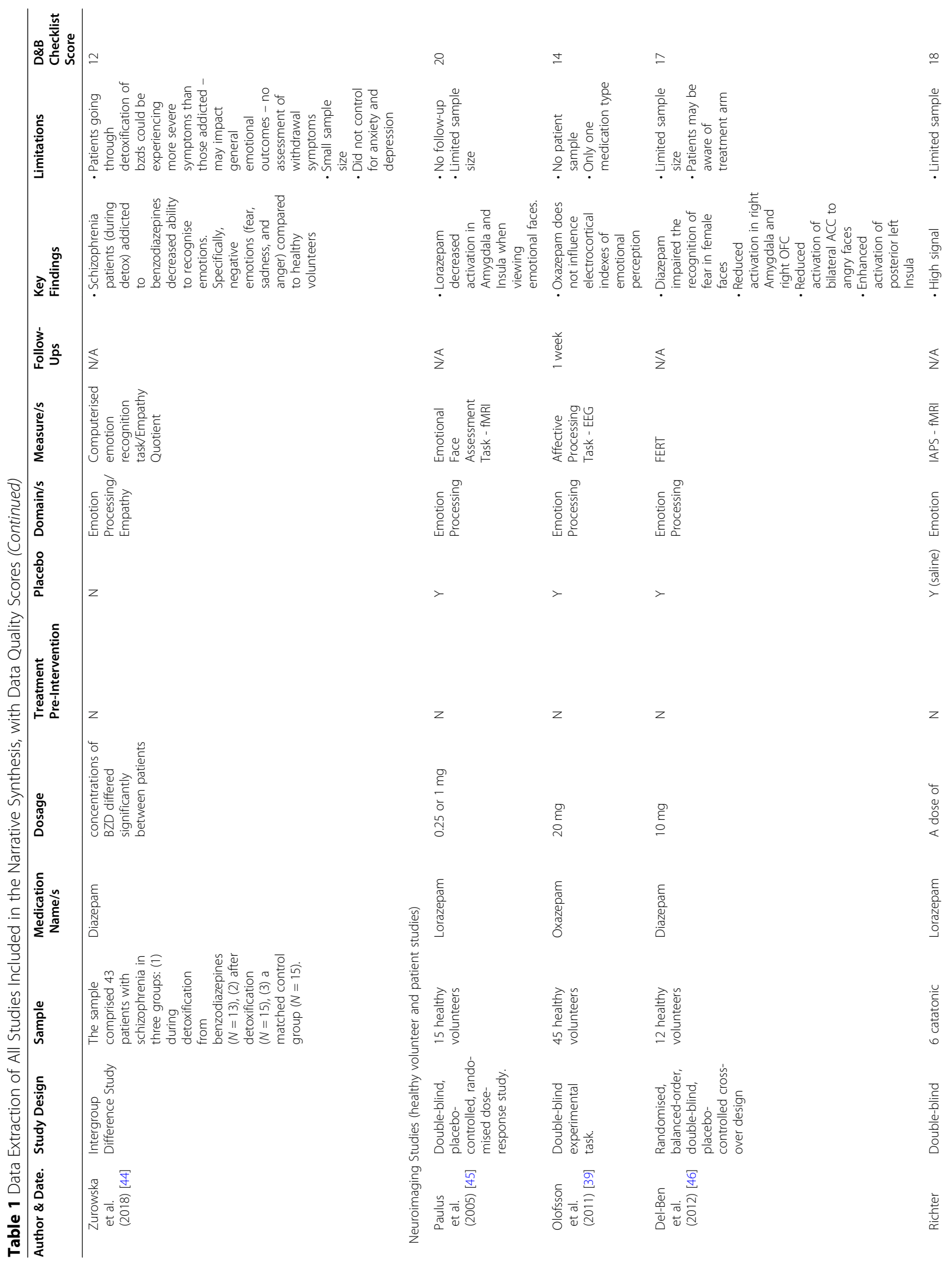




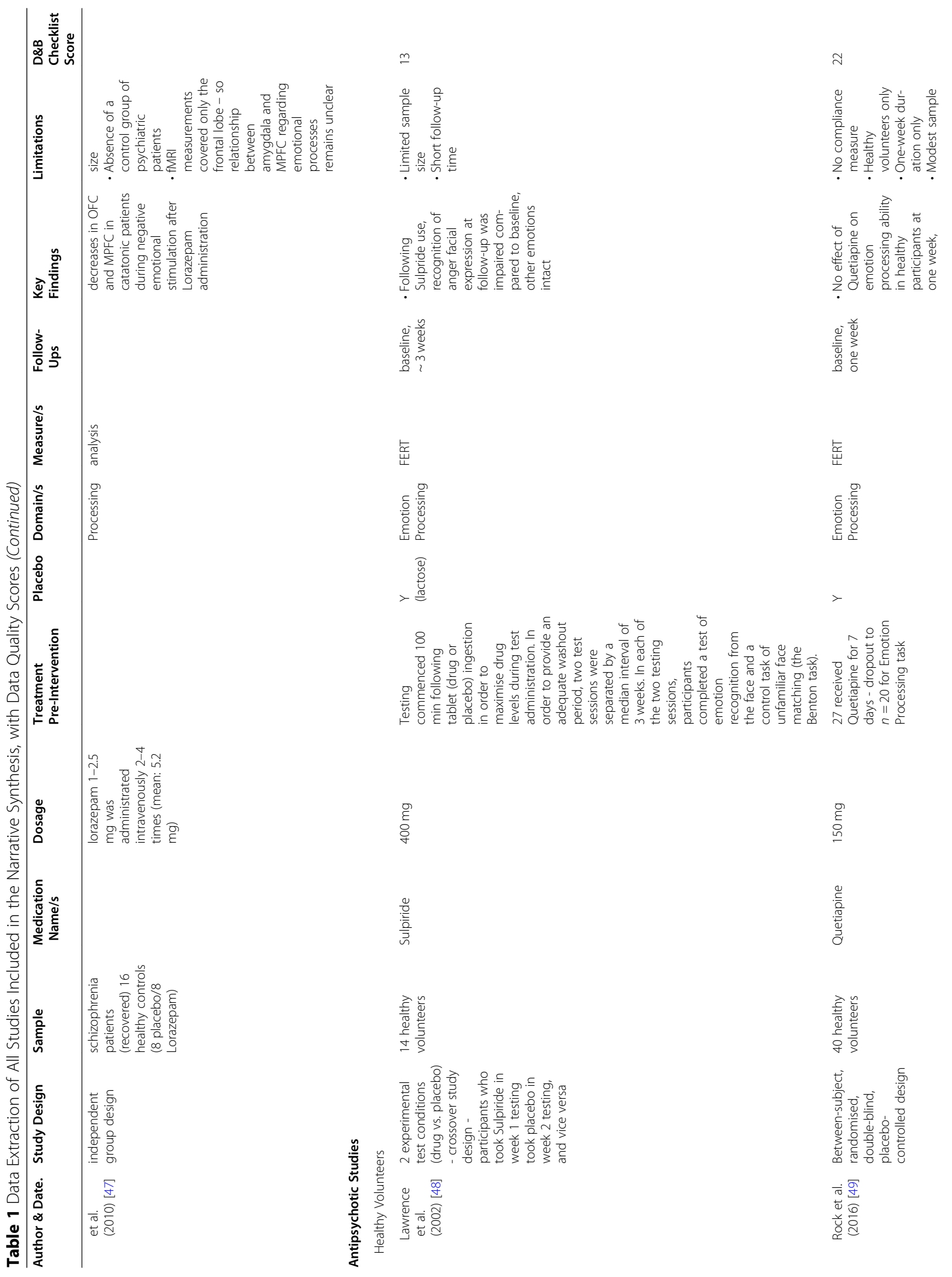




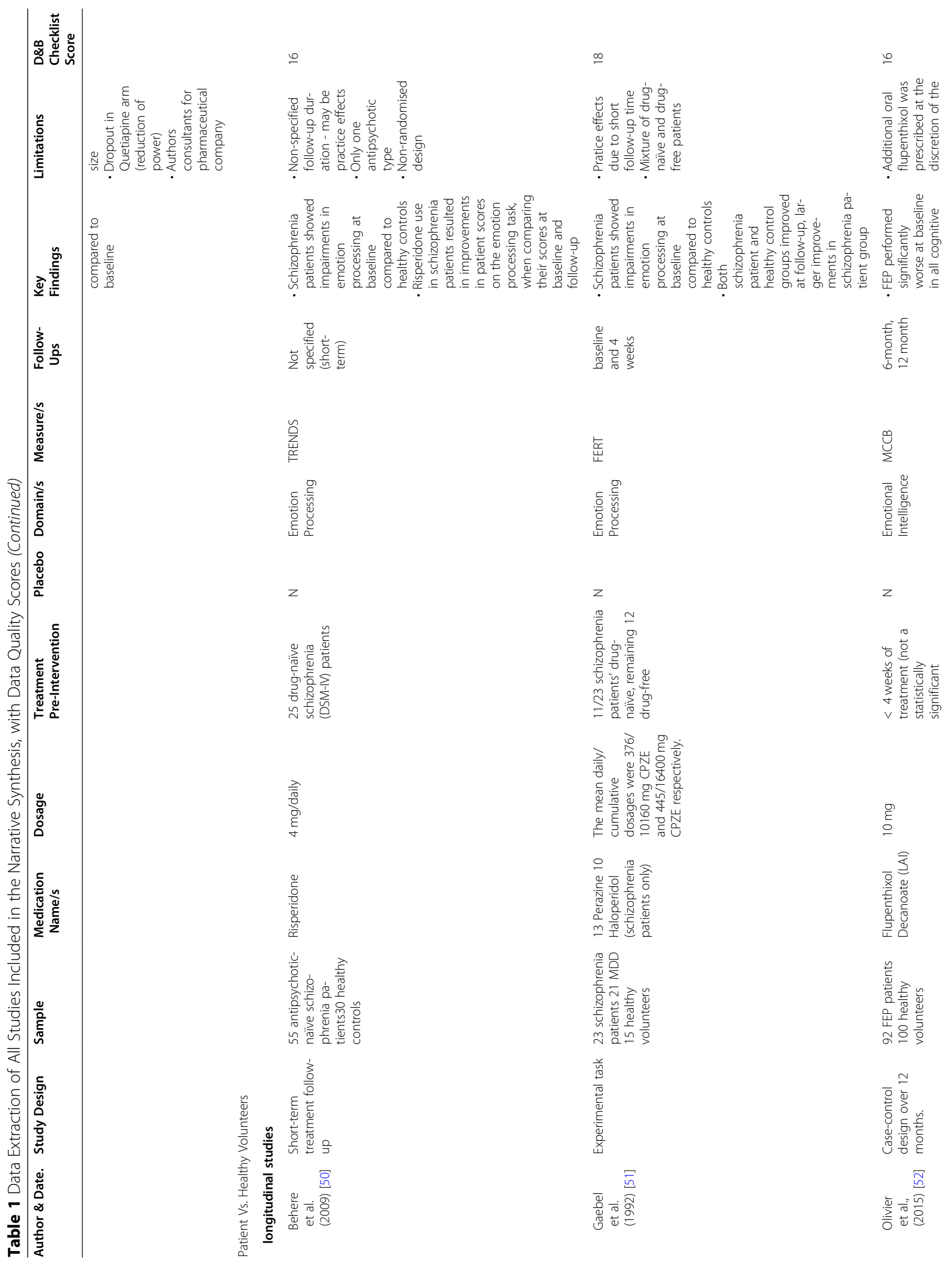




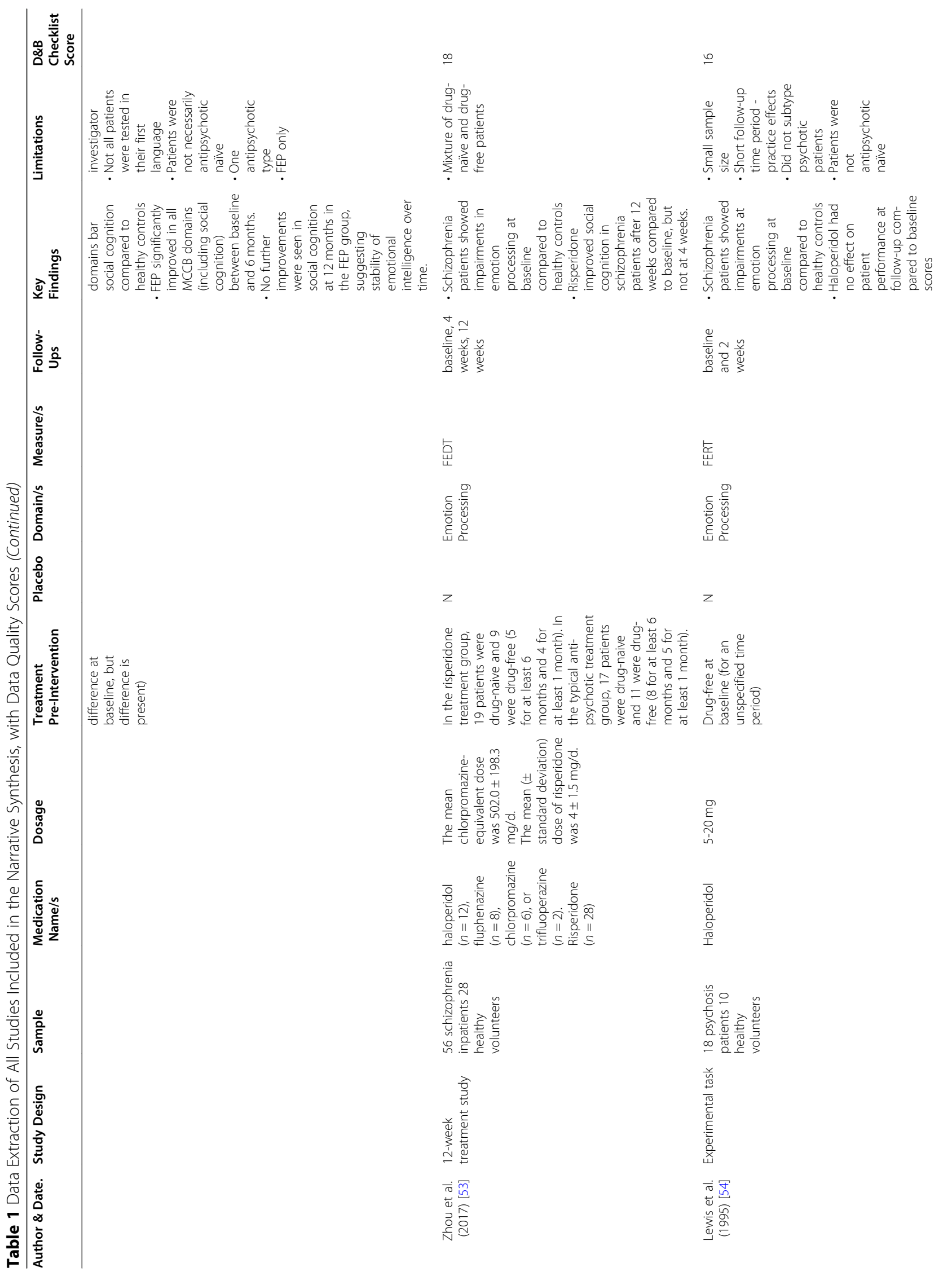




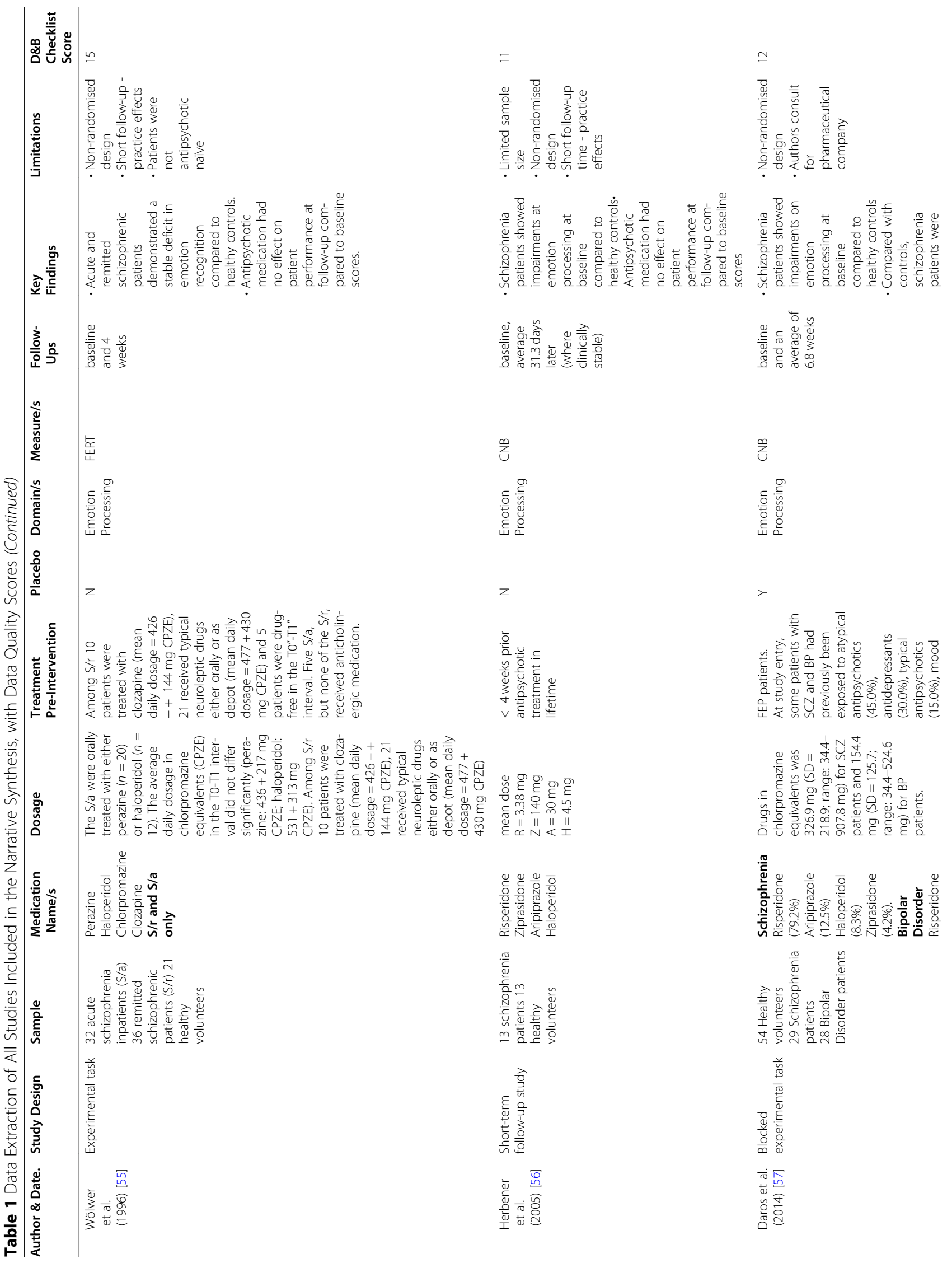




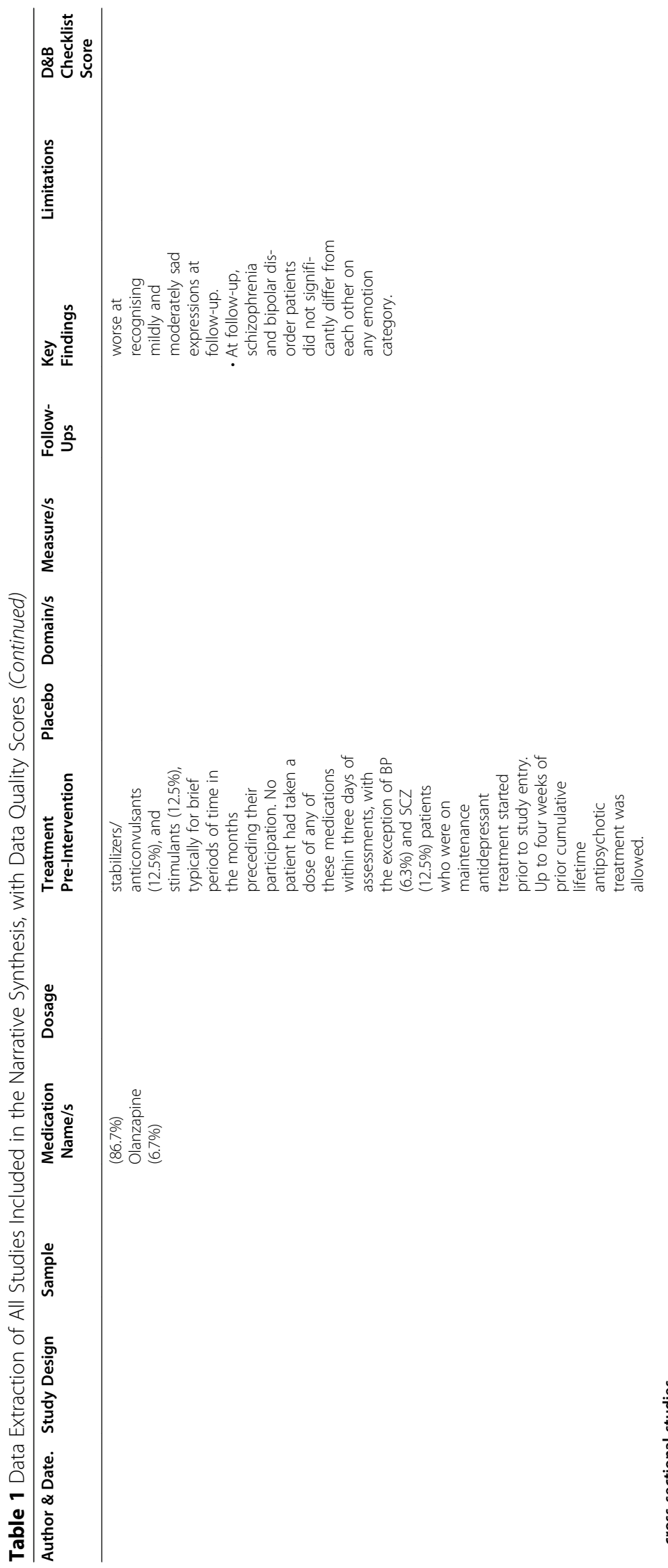

$\stackrel{n}{\sim}$

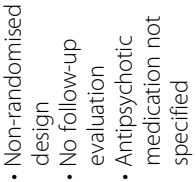

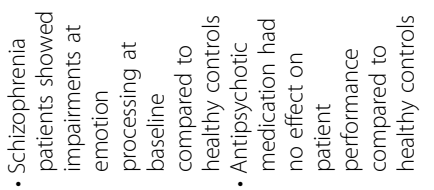

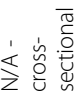

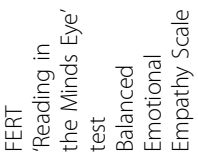

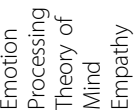

z

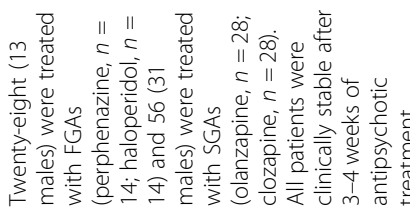

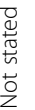

흘

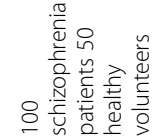

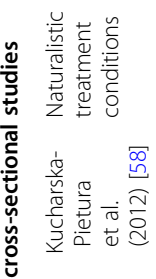

a

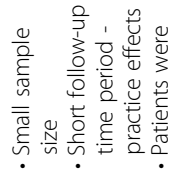

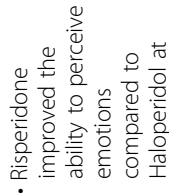

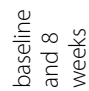

豈

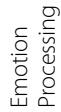

z

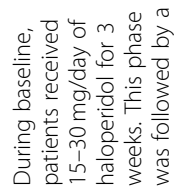

है छ

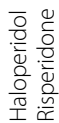

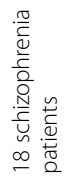

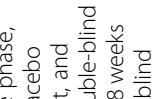

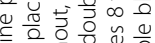

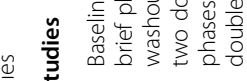




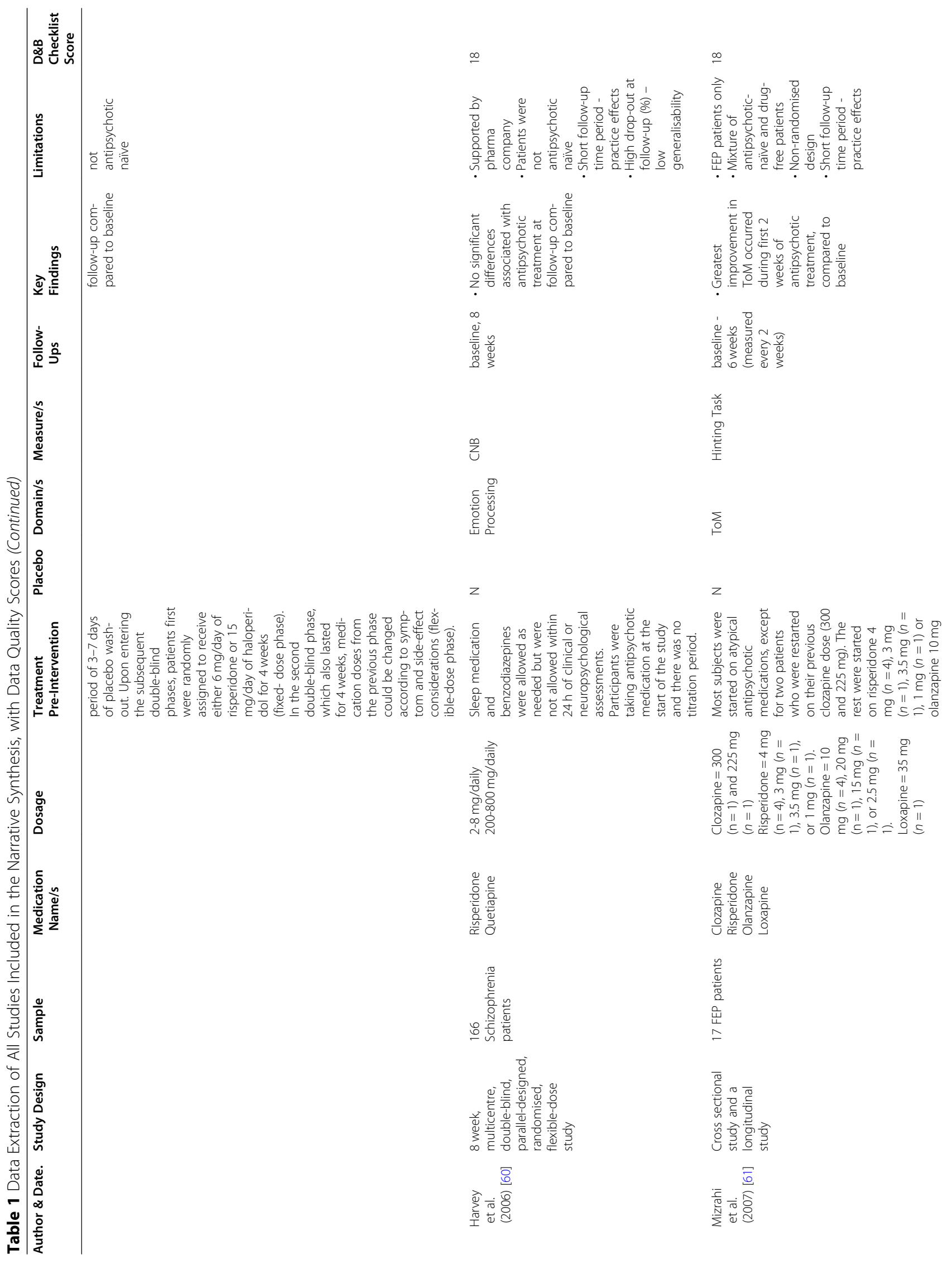




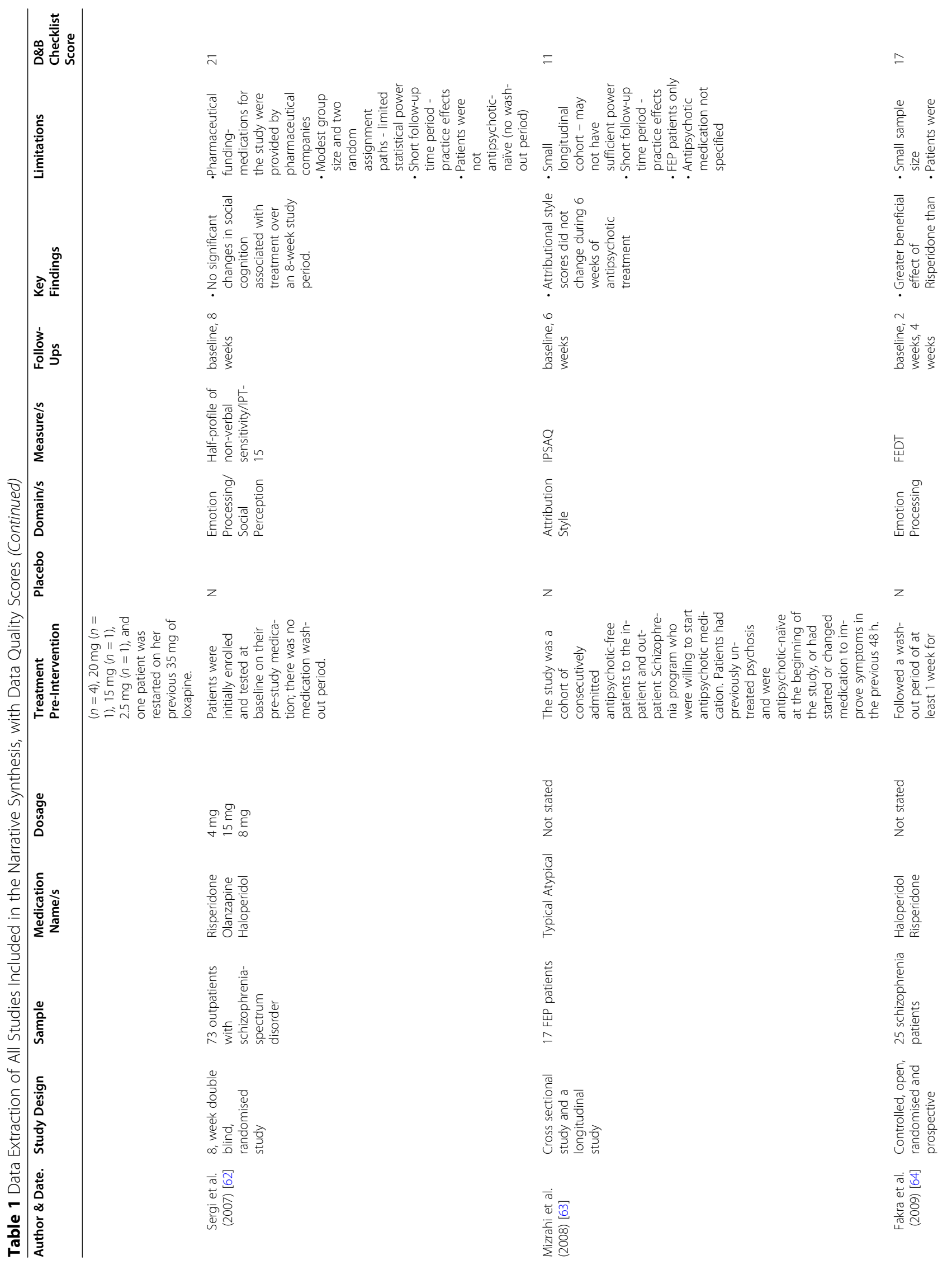




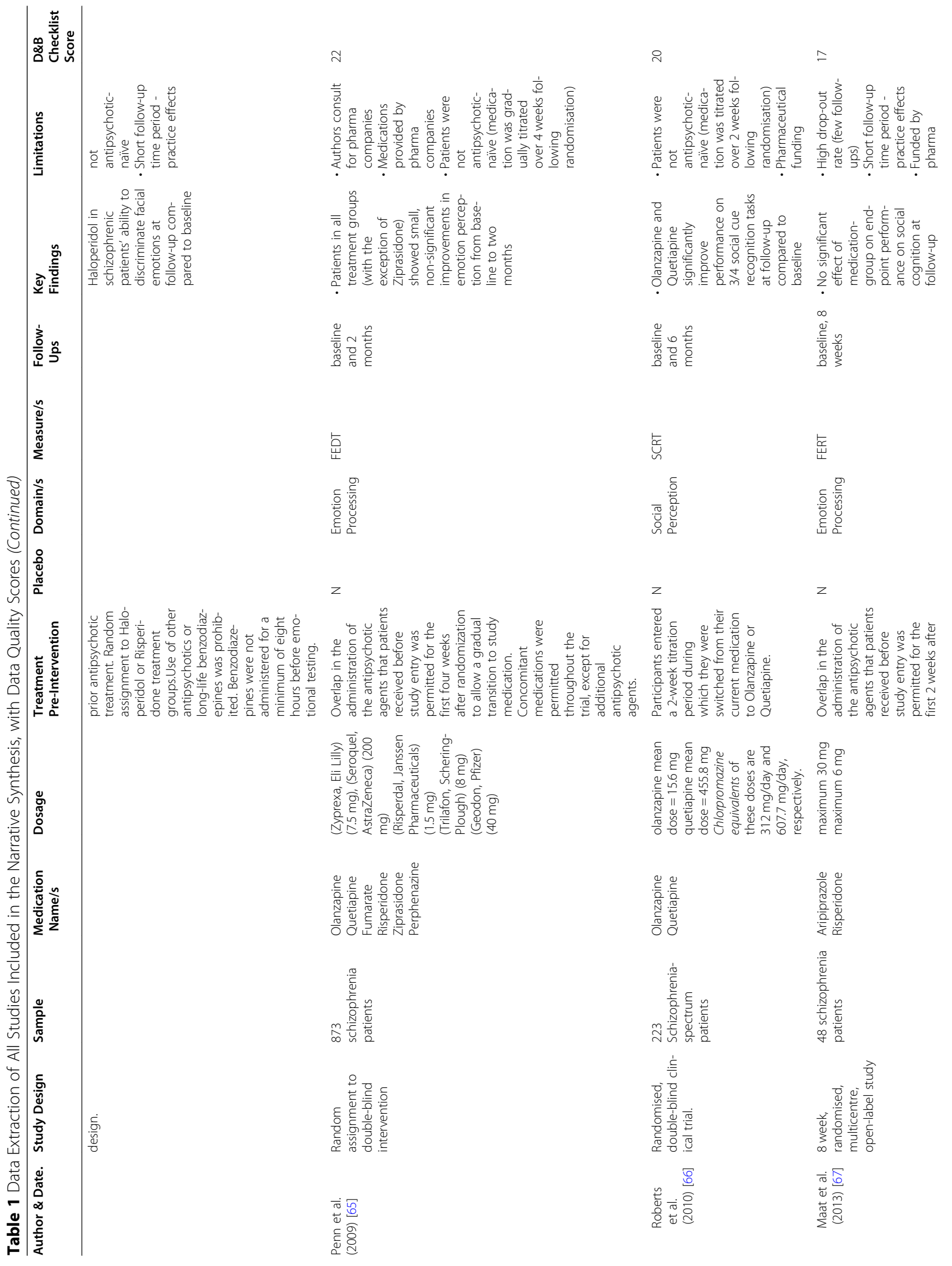




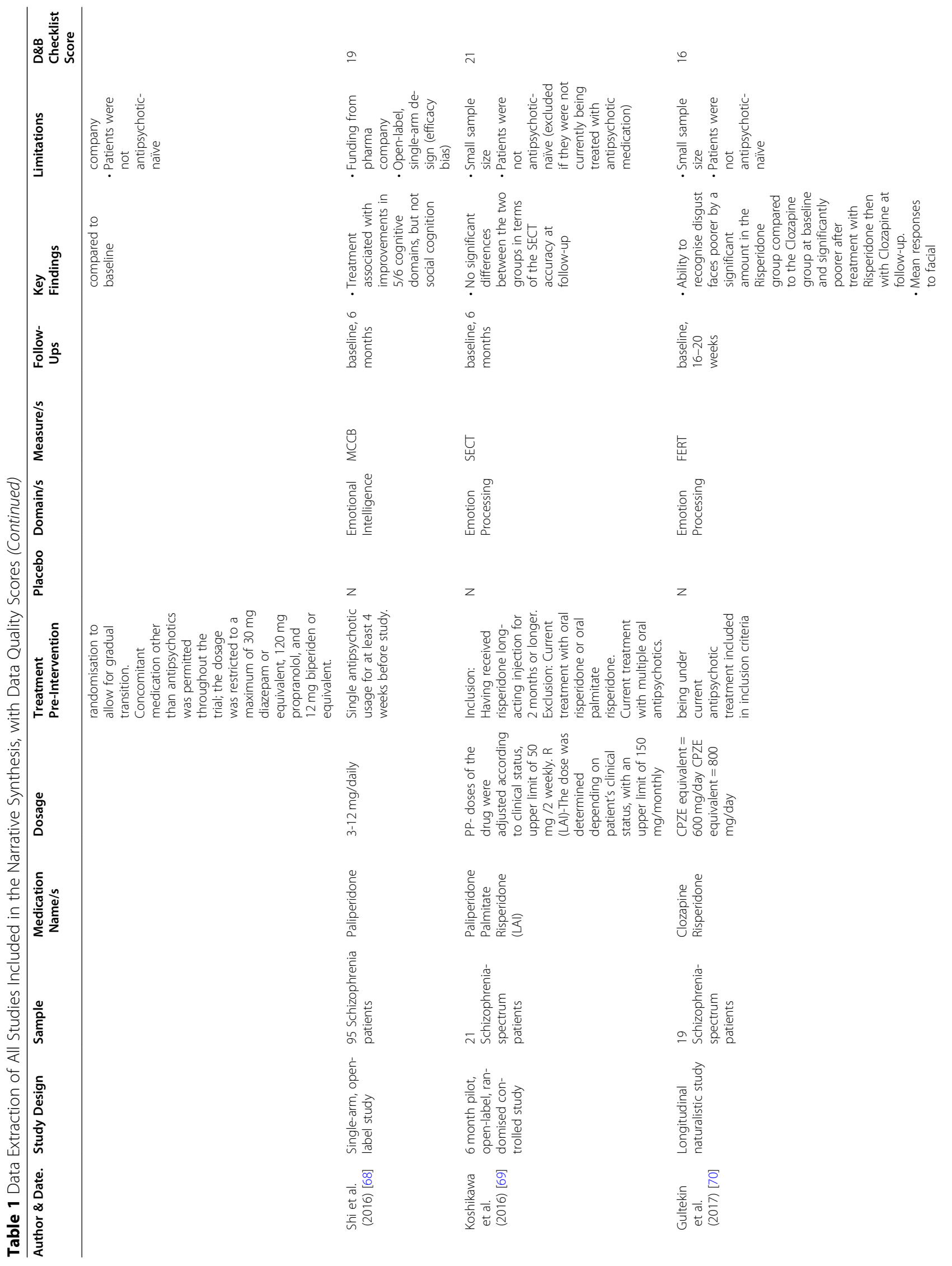




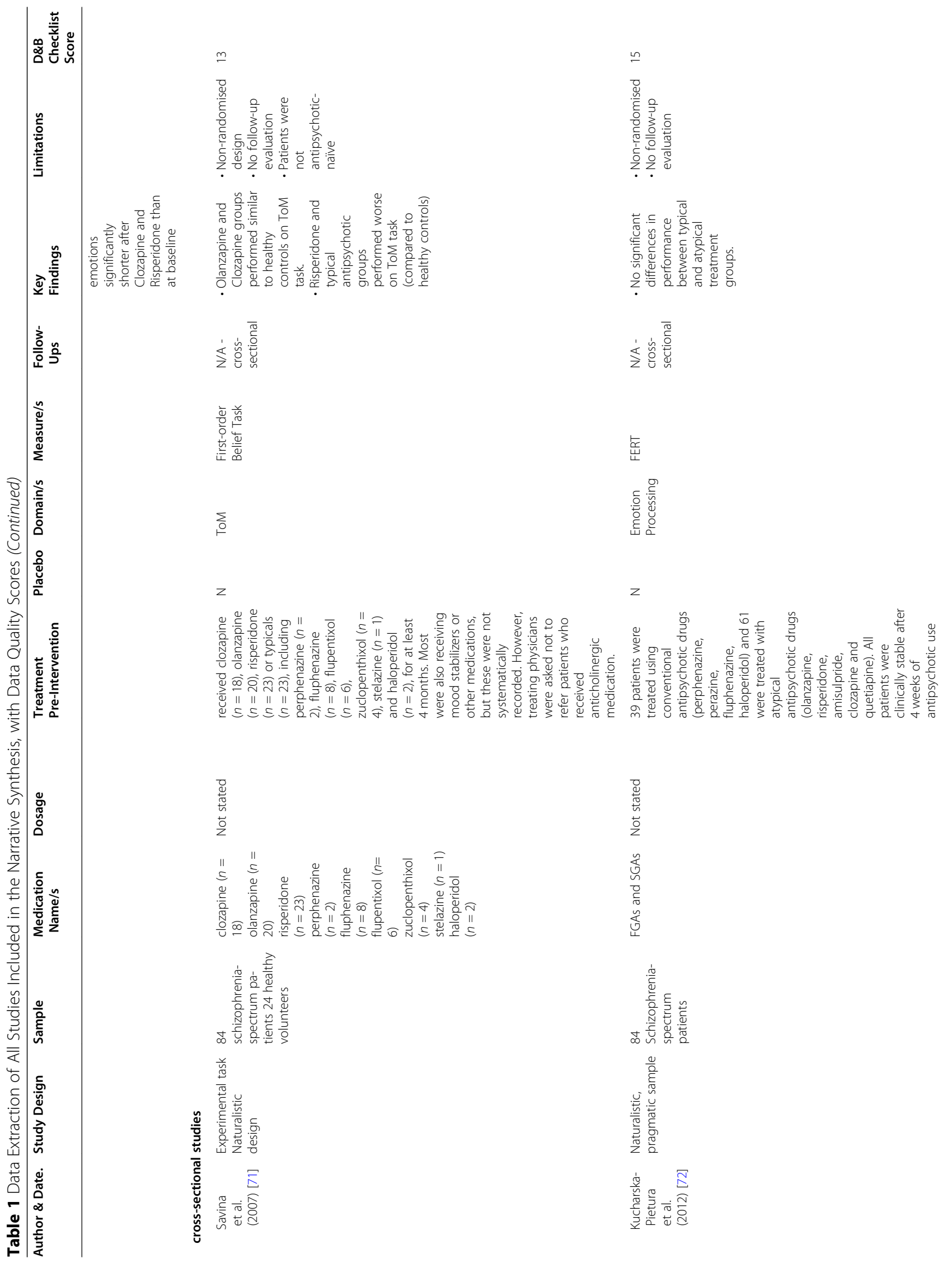




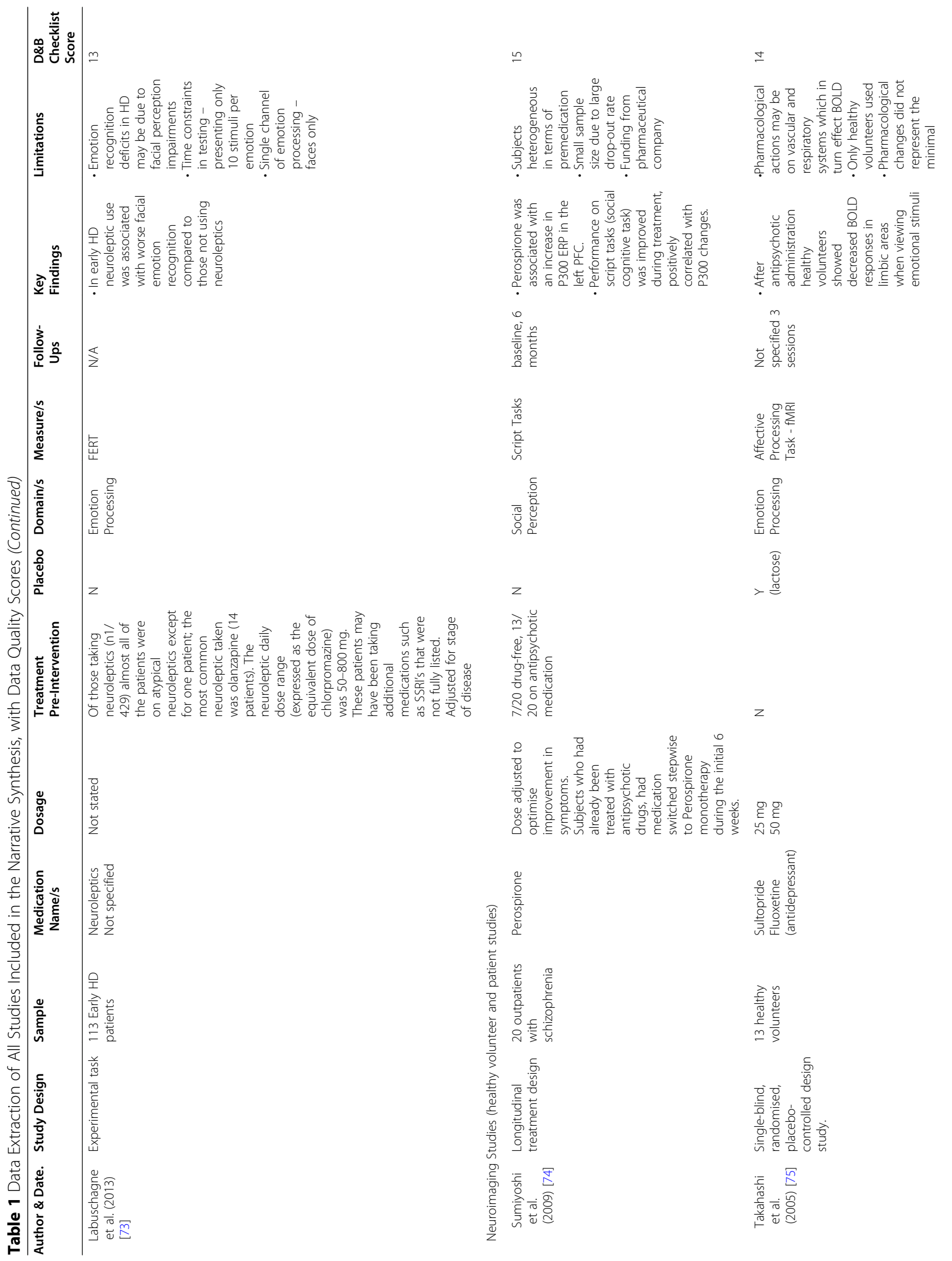




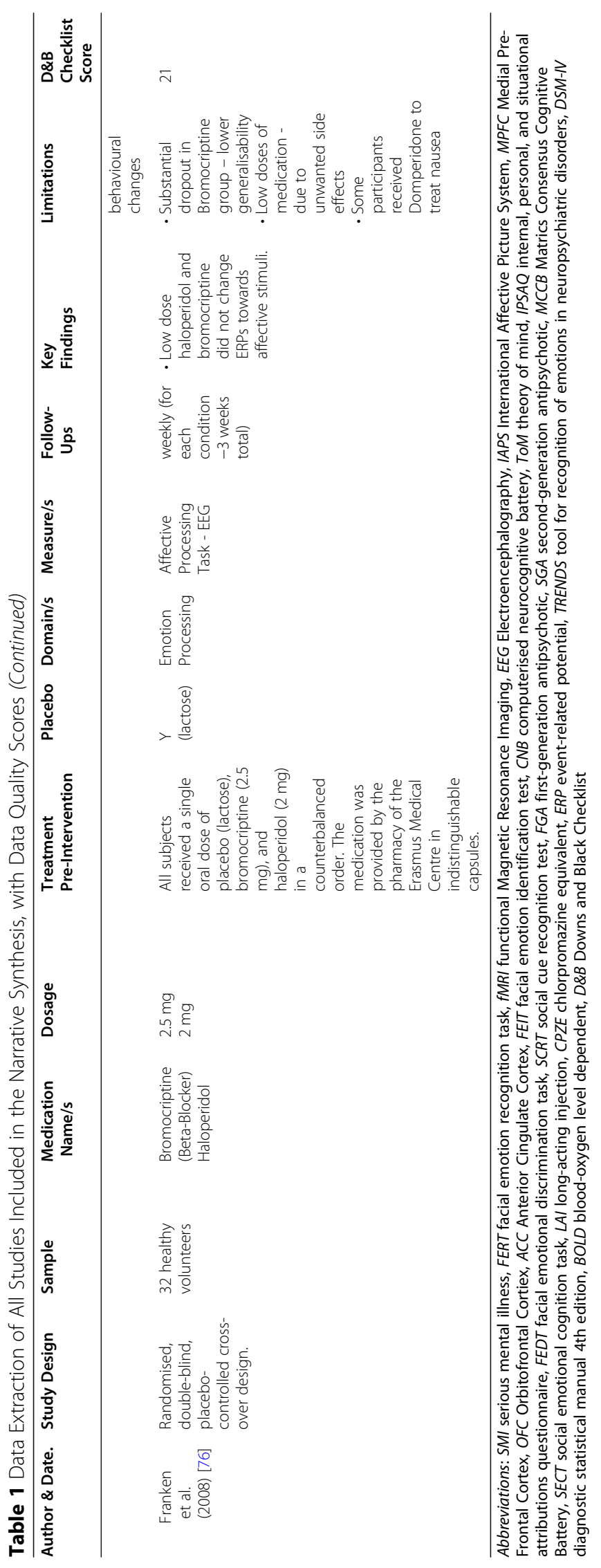




\section{Inclusion/exclusion criteria}

\begin{tabular}{ll}
\hline Inclusion Criteria & Exclusion Criteria \\
\hline $\begin{array}{l}\text { Longitudinal or cross-sectional study } \\
\text { designs }\end{array}$ & $\begin{array}{l}\text { Published in a non-English } \\
\text { language }\end{array}$ \\
Participants received or were being & $\begin{array}{l}\text { Qualitative, theoretical, or } \\
\text { systematic review or meta- } \\
\text { treated with a psychiatric }\end{array}$ \\
medication with sedative properties & $\begin{array}{l}\text { analysis papers } \\
\text { a }\end{array}$ \\
The population included healthy & \\
volunteers, humans with mental & \\
health or neuropsychiatric disorders & \\
Investigated a social cognition & \\
measure or task. & \\
Paper present in the initial search & \\
filtered for the following dates: & \\
From inception of database to 10th \\
August 2019. \\
Second search (on 30/12/2019): 10/ \\
08/2019-30/12/2019. \\
Study present in grey literature \\
searches on (greylit.org and \\
opengrey.eu) and fit all the above \\
inclusion criteria.
\end{tabular}

${ }^{a}$ We included all antipsychotics, benzodiazepines, Z-drugs, and barbiturates. Tricyclic antidepressants, mirtazapine and trazadone were also included, and pregabalin. Drugs that are prescribed for mental disorders but predominantly used for physical health complaints, such as gabapentin and beta-blockers, were excluded

\section{Screening}

Citations were imported to Mendeley and all duplicates were removed. $\mathrm{ZH}$ independently screened all citation titles for their applicability [77]. Titles that did not meet eligibility criteria were removed. Full-text papers were then screened and any uncertainties about inclusion were discussed with a second reviewer (AJW).

\section{Quality of assessment of studies}

Study quality was evaluated using the Downs and Black checklist [78] as it allows for assessment of both randomised and non-randomised studies. The checklist evaluates papers on reporting, external validity, and internal validity (bias and confounding). It consists of 27 items scored with 0 points for 'no/unable to determine', or 1 point for a 'yes' response. Item 5 is scored differently with 0 points for a 'no' response, 1 point for a 'partially' response, or 2 points for a 'yes' response. The last item on the checklist regarding power was altered in concordance with a previous review conducted by Trac et al. [79] to rate whether a power analysis was calculated (1 point), or not ( 0 points). The maximum score for the checklist was 28 , with the scoring ranges being $(<14)$ poor quality, (15-19) fair quality, (20-25) good quality, and (26-28) excellent quality.

\section{Results (narrative synthesis element 2: developing a preliminary synthesis) \\ Search results}

The search identified 2931 papers fitting the eligibility criteria, with 2681 remaining after de-duplication. The abstracts and titles of those records were then screened and 2511 were excluded due to not meeting the inclusion criteria. This resulted in 170 papers for full-paper screening. A further 130 papers were excluded during this stage, for reasons shown in Fig. 3. The remaining 40 full-text papers were used in the narrative synthesis. Data from these papers including study design, sample, medication (name, dosage), pre-intervention treatment, placebo (yes/no), social cognitive domains tested, social cognition measures, follow-up timepoints, key findings, and study limitations, were extracted and can be viewed in Table 1. Notably there were no studies of mood stabilisers, barbiturates, pregabalin or any sedative antidepressants.

\section{Quality of assessment of studies}

Data quality was rated by $\mathrm{ZH}$ on all 40 full-text papers and AJW on $20 \%$ randomly selected papers. An interrater reliability score Cohens Kappa Coefficient of 0.85 was calculated [80], indicating good agreement between authors. Of the 40 included papers, 11 were rated poor and 20 were rated fair. Only 9 total papers were rated good, and none were rated excellent. Scores for each paper are reported in Table 1.

\section{Benzodiazepine studies}

Four benzodiazepine studies conducted in healthy volunteers showed significant impairments in emotion recognition social cognition tasks following diazepam administration $[39,41,44,81]$, suggesting that sedative medication at a therapeutic dose impairs emotion processing. One of these papers also incidentally investigated the effects of Metropolol, a beta-blocker with mild sedative effects, and found no significant effect of the drug on emotion recognition [41]. A further study [42] showed a selective effect of diazepam on recognition of angry expressions only. This result may be due to using a small dose in comparison to other studies. One benzodiazepine study using oxazepam showed no effect on a measure of empathy [38].

One study was conducted in patients with schizophrenia, which looked at the effects of benzodiazepine withdrawal. Patients who were in the process of withdrawing from benzodiazepines were significantly impaired in recognising negative emotions compared to healthy volunteers, in contrast to patients who had already withdrawn, who were not. However, all patients were likely to have been on other medications [81]. 


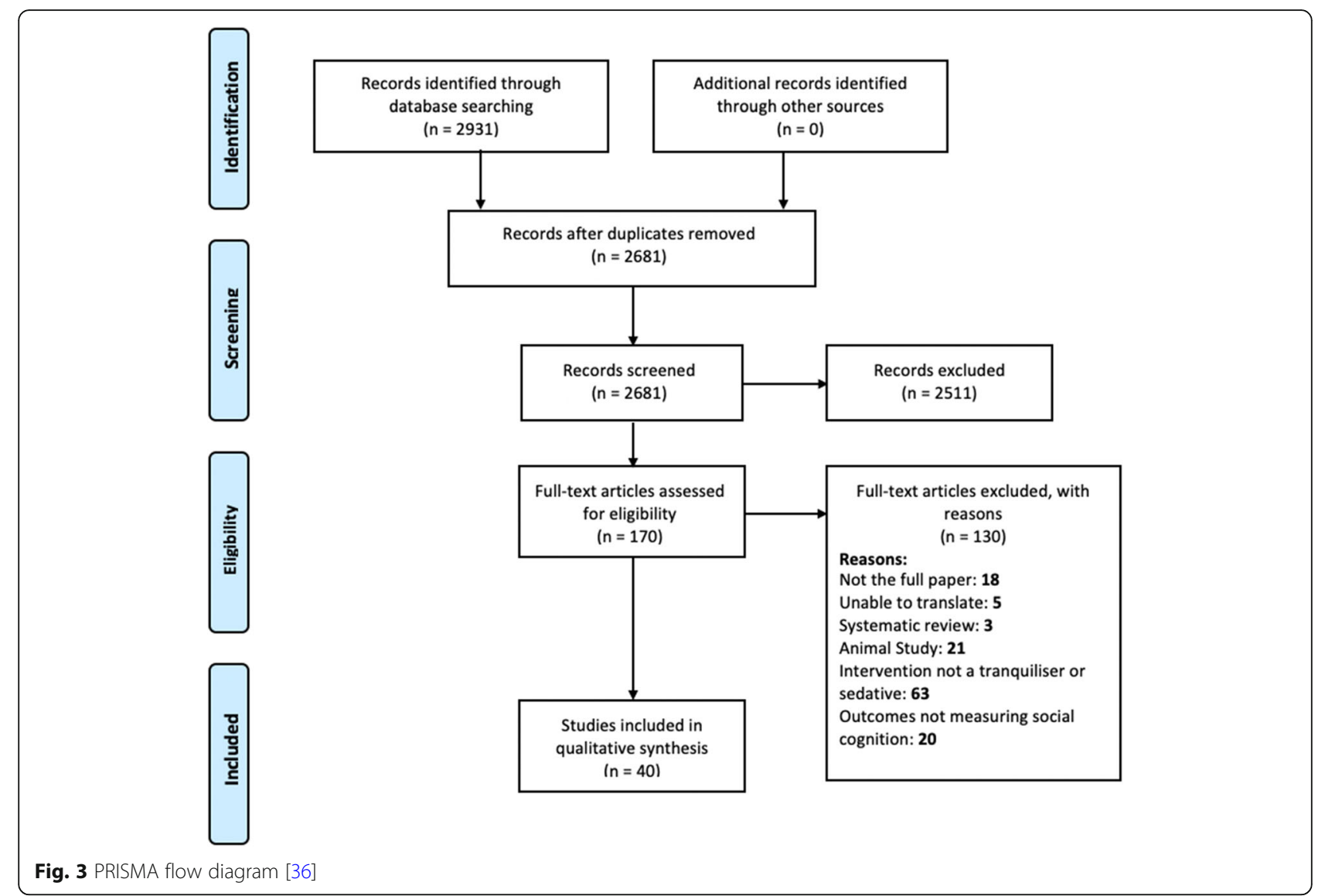

\section{Neuroimaging studies of benzodiazepines and social cognition}

All neuroimaging studies compared social cognition before and immediately after administration of the experimental drug. Del-Ben et al. [43] showed that a single dose of diazepam in healthy volunteers resulted in attenuated activation of the right amygdala when responding to fearful faces, although no evidence was found for this interaction when participants viewed angry faces. In another healthy volunteer study, Paulus et al. [82] showed that lorazepam attenuated activation in the amygdala and insula, and that the activation was significantly lower after $1 \mathrm{mg}$ compared to $0.25 \mathrm{mg}$, suggesting a dose-dependent reaction in emotional processing regions. However, a study by Olofsson et al. [45] found no interaction between benzodiazepines and EEG activity during response to an affective processing task.

A study investigating benzodiazepine effects on patients with 'catatonic' schizophrenia and patients with bipolar disorder found that lorazepam induced BOLD signal decreases in the occipital cortex and medial prefrontal cortex (MPFC) in patients with schizophrenia when undertaking a negative emotion recognition task. This resulted in BOLD patterns resembling those of healthy volunteers taking a placebo drug during the same emotion recognition tasks [46]. However, at the time of the fMRI task all patients were taking either antipsychotic or antidepressant medications in addition to the administered lorazepam.

\section{Antipsychotic studies Healthy volunteers}

Only two studies tested the effects of antipsychotics on social cognition in healthy volunteers. A small crossover study by Lawrence et al. [47] $(N=14)$ found that recognition of angry facial expressions was reduced in participants taking sulpiride, but recognition of other expressions was not affected. In addition, a larger randomised parallel group trial of quetiapine versus placebo by Rock et al. [48] $(N=27)$ found no effect of the medication on facial expression recognition, though dropout rates were high (25\%) in the quetiapine arm, which may have obscured an effect.

\section{Patient studies}

All studies comparing patients with schizophrenia and healthy volunteers found patients performed less well on social cognition tasks whether or not they were taking 
antipsychotics at baseline [49-54, 56, 61, 63, 68]. This included one study with patients who were drug naïve [61], two studies with patients who were drug-free at study commencement $[53,68]$, studies including participants with a mixture of drug-naïve, drug-free, and previous treatment for under 4 weeks [50-52, 54, 57, 72], and one study with patients stable on an antipsychotic [58]. Most longitudinal studies involving people with schizophrenia taking antipsychotics showed improvements in performance on social cognition tasks at follow-up compared to baseline [50-52, 55, 56, 59, 61, 63, 64, 66, 70], although some found no effect $[49,53,54,58,60,62,65$, 67] and one showed a decline [68].

When studies were classified by the prior medication status of participants, two longitudinal studies involved patients who were previously drug naïve. One of these studies detected improvements on an emotional processing task at follow-up [61], the other study involved an attributional style task, and found no effects of the medication [49]. Studies that involved patients who had a prior drug-free period, mostly found improvements in emotion processing tasks $[50,52,53,70]$, and one in a theory of mind task [56]. Some studies specified that participants were taking an antipsychotic at baseline prior to switching to another $[51,54,55,58-60,62-65$, $67,68]$ and one did not describe the prior treatment status of participants [66]. In studies in which people were already taking antipsychotic treatment, results reflect effects of changing the type of antipsychotic rather than starting treatment.

One study tested healthy volunteers at baseline and follow-up to control for practice effects [50]. It found that patients with schizophrenia treated with antipsychotics (a mixture of people who were previously drug naïve $(n=11)$ or drug free $(n=12))$ showed significant improvements in emotion recognition at 6 months compared to healthy volunteers.

One longitudinal study involving 29 people with schizophrenia and 28 with bipolar disorder explored dose-response relationships [68]. Findings showed that patients with schizophrenia who were taking higher doses of antipsychotic medication had more difficulty recognising sad and neutral facial expressions compared to those taking lower doses at follow-up. In bipolar patients, antipsychotic dose was unrelated to the accuracy of performance in judging emotions.

Studies comparing different antipsychotics produced inconsistent results. Some found that patients treated with second-generation drugs did better than those taking first-generation antipsychotics $[55,59,66,69,70]$, but there was no consistent pattern to the results. Others found no difference between different agents or types of agent [57, 60, 62, 65, 67, 72]. The largest study by Penn et al. [64] showed improvements in all treatment groups (except for ziprasidone) on an emotion processing task, with no difference between individual second-generation drugs or between first- and secondgeneration drugs.

One study involving participants with Huntingdon's disease showed poorer performance on facial recognition tests in those taking antipsychotics compared to those who were not, after controlling for the stage of the disease [71].

In this review, several studies were conducted by authors who received funding from pharmaceutical companies for research purposes or consulting. One study had a pharmaceutical company provide the medication for the research [65]. Studies that were conducted by authors who received pharmaceutical company funding found either improvements in social cognition after antipsychotic administration [55, 64, 73], or no effect of the drug on performance $[60,63,65]$. However, improvements were also shown in studies that did not rely on pharmaceutical funding $[50-52,56,61,66]$.

\section{Neuroimaging studies of patients and social cognition}

A study by Sumiyoshi et al. [73] investigated the effect of the antipsychotic, perospirone, on social perception in schizophrenia patients. They found an increase in the P300 ERP activation in the left pre-frontal cortex (PFC), as well as improvements in the social cognitive script task, after 6 months treatment compared to baseline.

A study investigating the effect of sultopride on emotion processing in healthy volunteers found decreased BOLD responses in the amygdala when viewing negatively valenced stimuli compared to before sultopride administration [74]. There was also increased activation in the PFC identified during positron emission tomography (PET) scans. However, behaviourally they found minimal changes to performance on social cognition tasks. Additionally, a crossover EEG study by Franken et al. [75] with healthy volunteers, found that both the dopamine agonist bromocriptine, and antipsychotic haloperidol produced no significant difference in emotion-related ERPs (P300-P400) compared to before drug administration. This study used low doses of medication, however, and some participants were also prescribed domperidone to treat nausea.

\section{Discussion (narrative synthesis element 3: exploring the relationships within and between the studies)}

Clarifying the effects of prescribed medication on social cognitive ability is important since social cognition appears to be impaired in people across psychiatric diagnoses, and this impairment may be related to deficits in social functioning that represent a significant disability. Hypothetically, psychiatric drugs may impair social 
cognition due to their sedative effects, or may, through improving psychiatric symptoms, benefit social cognition.

The findings suggest that psychiatric drugs with sedative properties, such as benzodiazepines, can impair emotion recognition in healthy volunteers $[39,41,42$, $44,81]$. Findings were most consistent for emotion processing following the use of diazepam, however few studies were conducted using other benzodiazepines or measures of social cognition. Two neuroimaging studies investigating lorazepam found decreased activation in the social cognitive neural network during emotion processing [46, 82]. These findings suggest sedative effects of lorazepam may be altering brain processes required for emotion recognition, although neither study used a behavioural measure to confirm the effects on social cognitive ability. In contrast effects of antipsychotics on healthy volunteers were inconsistent, but only two studies were identified. As antipsychotics have different pharmacological profiles and cause varying levels of sedation, different agents may have different effects. Further research is required to clarify effects of antipsychotics on social cognition in volunteers, especially considering the evidence that antipsychotics impair neurocognitive performance and their reported effects on emotional reactivity.

Results of studies with patient populations found that antipsychotic treatment improves or has no effect on social cognition in patients with schizophrenia. The studies suffered from several important methodological limitations, however. First, practice effects in cognitive tasks are common [76], and as most studies in this review had short follow-up time windows (averaging 3.2 months) it is expected that improvements would be caused by task memory from earlier sessions. Only one study controlled for practice effects by including a healthy volunteer control group. The study identified practice effects, but also showed an additional improvement in social cognition that was independent of practice effects [51]. Second, studies did not distinguish the effects of the medication from the effects of changes in symptoms. Symptom improvement may occur as a result of antipsychotic treatment but may also occur spontaneously. One of the present studies detected a correlation between psychotic symptoms and social cognition [53], but ultimately, placebo-controlled comparisons are needed to reliably detect treatment-specific effects.

In contrast to studies showing improvement in social cognition with antipsychotics, one study on emotion processing identified a negative effect with a doseresponse relationship, such that higher doses of antipsychotics related to higher levels of social cognitive impairment in patients with schizophrenia, but this was only found in people diagnosed with schizophrenia and not with bipolar disorder. The study with patients with Huntingdon's disease also found worse facial recognition performance associated with antipsychotic use, even after adjusting for disease severity [71]. This is consistent with the evidence of reduced neurocognitive functioning in people with Alzheimer's following antipsychotic use, but further studies are required to clarify the effects of drugs in other psychiatric conditions.

Patients who experience psychiatric disorders are likely to experience neurocognitive deficits such as poor attention and decision-making skills due to the nature of their symptoms [83], which may directly prevent successful social cognitive ability [27]. In addition to this, some research has found that patients with a mental health diagnosis are more likely to have poorer intellectual abilities than the healthy population [84], which could result in difficulties with language and communication skills. These difficulties may make individuals less experienced or confident in a social environment and have a negative influence on social cognition as a result. The studies examined here confirmed that there is an impairment of social cognition in people experiencing a psychotic episode, even before drug treatment is started. However, the research base is currently not adequate to unravel whether there are additional positive or negative effects associated with the use of psychiatric drugs.

Neuroimaging findings suggest that medication may be affecting brain processes that have been found to be associated with social cognitive ability. Sumiyoshi et al. [73] found an increase in the P300 ERP during a social perception task in patients with schizophrenia after antipsychotic administration, which was positively correlated with their task performance. However, only 7 of 20 participants started the study drug-free, and 8 participants dropped out after the baseline assessment, making it difficult to make firm conclusions. Takahashi et al's [74] study on an affective processing task showed decreased BOLD responses in the amygdala and greater activations in the PFC following antipsychotic administration in healthy volunteers. This was noteworthy as the PFC is known to attenuate amygdala activation during emotional processing [85]. Therefore, it is possible antipsychotic medication is working directly on the PFC, and decreased amygdala signals are secondary to this.

\section{Strengths and limitations (narrative synthesis element 4: assessment of the robustness of the synthesis)}

One of the most important strengths of this review was establishing the current literature on the effects of sedative psychiatric medications on social cognition using a rigorous search strategy of published and unpublished work.

We included all psychiatric populations, and healthy volunteer studies in our search. However, in our review 
we found the research was largely limited to studies of benzodiazepine effects in healthy volunteers, and studies of antipsychotics in patients with schizophrenia with one study of patients with the neuropsychiatric disorder, Huntingdon's disease [86]. Research on neurocognitive function suggests that antipsychotics, in particular, may have specifically detrimental effects in people with psychiatric disorders, such as Alzheimer's, and further research on their effects on social cognition in people with these disorders would be valuable.

We made efforts to also include all prescribed psychiatric medications with sedative effects in our search, but we may have omitted some medications that are not commonly used. We also excluded drugs that are prescribed for mental disorders but are predominantly used for non-psychiatric indications, such as gabapentin or beta-blockers. We also did not include drugs with sedative effects that are routinely used for physical disorders, such as opiate anaesthetics, for example, and we also did not include recreational sedatives such as alcohol or heroin in our search. The review focused on prescribed psychiatric medication in order to clarify the effects of these medications in people with diagnoses of mental disorders, but recreational drugs are commonly used amongst patients with a mental health diagnosis [87], and their sedative effects may also influence social cognitive ability. Therefore, this should be an important consideration for future research in the area.

An integral strength of our search for this review was the inclusion of all known terminology for social cognitive domains and measures. However, this was difficult due to the use of interchangeable terms for similar items, exposing a feature of the social cognition field that needs to be addressed.

A limitation of the current review was the poor quality of available studies. Our data quality analysis tool allowed us to identify several deficiencies with current papers available in the field, such as small sample sizes, non-randomised designs, and few adherence to medication measures. Only four of the studies found conducted power analysis to qualify their sample size. This resulted in many of the included studies having small numbers of recruits, undermining the internal and external validity of the research findings. During quality analysis, researchers also found only three of the longitudinal studies included were recording medication adherence. In addition to this, very few studies considered the influence of practice effects, which have an important influence on the results of longitudinal studies of cognitive performance, and there were few randomised placebocontrolled studies that would allow conclusions about whether changes in patients taking antipsychotics were attributable to specific medication effects, or whether they were the result of unrelated symptom improvement or of practice effects. Additionally, only one study of antipsychotics, and no benzodiazepine studies, looked at dose-dependent effects. This variability in studies also restricted analysis of the papers included, making a meaningful meta-analysis impossible to conduct.

One other major limitation of this review was that $80 \%$ of the included studies explored emotion processing tasks, leaving the other domains of social cognition largely ignored in the literature. Resultingly, our review is more of an insight into the effects of sedative medications on emotion processing, rather than the broader area of social cognition as a whole.

Finally, benzodiazepines have reasonably consistent effects, but antipsychotics vary widely in their receptor targets, pharmacological actions and sedative profiles [47, 48]. The studies examined did not enable a comprehensive comparison of the effects of different agents within any class of drugs. In addition, no studies were found that assessed effects of other prescribed psychiatric drugs with sedative properties, such as mood stabilisers, sedative antidepressants or pregabalin.

\section{Further research}

We suggest that further research of higher quality is needed to clarify the effects of sedative medications on social cognition in healthy volunteers and patients with psychiatric diagnoses.

Further studies conducted with neuroimaging techniques will allow better insight into structural or functional brain changes resulting from administration of psychiatric medication with sedative effects. Conducting these studies with a behavioural performance element will also allow researchers to identify if brain changes are consistent with changes in social cognitive ability.

Further studies also need to control for practice effects, and studies involving patients should include placebo or no treatment control groups in order to distinguish the effects of medication from the natural evolution of psychiatric symptoms. Studies should be conducted across a range of social cognition domains, to ensure we are getting an accurate picture of complete social cognitive ability. Additionally, studies should be conducted across a range of psychiatric medications with sedative properties, to ensure we are able to identify any significant differences between drugs, and in different psychiatric diagnoses to clarify the effects of medication across conditions.

Notably, recent research in the field of social cognition and psychiatry has focused on the potential benefits of non- pharmacological interventions, such as social cognition and interaction training (SCIT), metacognitive reflection and insight therapy (MRIT), and metacognitive training. A review in 2009 by Choi and colleagues [88] found that five intervention studies showed promising 
results for social cognitive improvements in patients with schizophrenia, and a comprehensive review by Kurtz et al. [89] showed large effect sizes for training on facial affect recognition, moderate effect sizes on theory of mind, and small effect sizes on attribution bias for patients with schizophrenia. Although some studies included in these reviews used control groups, the majority of studies failed to control for potential medication effects in participants with schizophrenia. Psychiatric medication use alongside a social cognitive training intervention may cause improvements or deficits in participant outcomes, which we consider an important clinical implication in treatment implementation. Therefore, we suggest future research in this area accounts for psychiatric medication use in the analysis of intervention effectiveness.

\section{Conclusion}

Deficits in social cognition have been identified in people with psychiatric diagnoses, and are associated with impaired social functioning, yet we remain uncertain to what extent these are attributable to the effects of the disorder or the effects of its treatment. A number of healthy volunteer studies suggest that diazepam and lorazepam can impair emotion processing abilities. Studies on antipsychotics were inconclusive and suffered from methodological limitations. There were no studies on any other drugs with recognised sedative properties, and studies focused mainly on the emotion processing domain of social cognition. Better data on the ability of drugs to affect social cognition will help to improve our understanding of the nature of social cognitive deficits in mental disorders, and the effects of treatment. Optimising the treatment of social cognition could potentially lead to better social functioning outcomes.

\section{Supplementary Information}

The online version contains supplementary material available at https://doi. org/10.1186/s12888-021-03545-z.

Additional file 1: Appendix A. Literature Search Strategy.

\section{Acknowledgements}

EMJ is supported by the UCLH/UCL NIHR Biomedical Research Centre.

\section{Code availability}

Not Applicable.

\section{Authors' contributions}

$\mathrm{ZH}, \mathrm{AJW}, \mathrm{NC}$ and $\mathrm{JM}$ contributed to the design of this review. $\mathrm{ZH}$ developed the protocol with supervision from NC and JM. ZH and AJW were involved in conducting the literature search and data extraction. ZH consulted LM on analysis for the systematic review. ZH, AJW, NC, and JM defined the themes of the narrative synthesis. $\mathrm{ZH}$ took the lead on writing the manuscript, with comments and support from all authors. The author(s) read and approved the final manuscript.

\section{Funding}

This research was funded by North East London Foundation Trust supporting the PhD study of first author $\mathrm{ZH}$.

Availability of data and materials

Not Applicable.

\section{Declarations}

Ethics approval and consent to participate

Not applicable.

Consent for publication

Not applicable.

\section{Competing interests}

JM is chief investigator for the NIHR-funded RADAR study of antipsychotic reduction. All other authors do not have any conflict of interest.

\section{Author details}

${ }^{1}$ Psychiatry Department, University College London, London, UK. ${ }^{2}$ Institute of Neurology, UCL, London, UK. ${ }^{3}$ Department of Primary Care and Population Health, UCL, London, UK.

Received: 23 June 2021 Accepted: 14 October 2021

Published online: 29 November 2021

\section{References}

1. Ostrom T. In: Wyer Jr RS, Srull TK, editors. The sovereignity of social cognition, in Handbook of social cognition. Hillsdale: Erlbaum; 1984. p. 1-38.

2. Ospina LH, Nitzburg GC, Shanahan M, Perez-Rodriguez MM, Larsen E, Latifoglu $A$, et al. Social cognition moderates the relationship between neurocognition and community functioning in bipolar disorder. J Affect Disord. 2018;235:7-14. https://doi.org/10.1016/j.jad.2018.03.013.

3. Weightman MJ, Air TM, Baune BT. A review of the role of social cognition in major depressive disorder. Front Psychiatry. 2014;5:179.

4. Green MF, Horan WP, Lee J. Social cognition in schizophrenia. Nat Rev Neurosci. 2015;16(10):620-31. https://doi.org/10.1038/nrn4005.

5. Augoustinos M, Walker I, Donaghue N. Social cognition: an integrated introduction. 2nd ed. London: Sage; 2006.

6. Green MF, Penn DL, Bentall R, Carpenter WT, Gaebel W, Gur RC, et al. Social cognition in schizophrenia: an NIMH workshop on definitions, assessment, and research opportunities. Schizophr Bull. 2008;34(6):1211-20. https://doi. org/10.1093/schbul/sbm145.

7. Taylor SE, Fiske S. Social Cognition, from Brains to Culture. 3rd ed. London: SAGE; 2017

8. Baron-Cohen S. Theory of mind in normal development and autism. Prisme 2001;34:174-83.

9. Lemerise EA, Arsenio WF. An integrated model of emotion processes and cognition in social information processing. Child Dev. 2000;71(1):107-18. https://doi.org/10.1111/1467-8624.00124.

10. Hamilton DL, Sherman SJ. Perceiving persons and groups. Psychol Rev. 1996;103(2):336-55. https://doi.org/10.1037/0033-295X.103.2.336.

11. Garety PA, Freeman D. Cognitive approaches to delusions: a critical review of theories and evidence. Br J Clin Psychol. 1999;38(2):113-54. https://doi. org/10.1348/014466599162700.

12. Spelke ES, Bernier EP, Skerry AE. In: Banaji MR, Gelman SA, editors. Core social Cognition, in navigating the social world: what infants, children, and other species can teach us. New York: Oxford University Press; 2013.

13. Cohen S. Social relationships and health. Am Psychol. 2004;59(8):676-84. https://doi.org/10.1037/0003-066X.59.8.676.

14. Hannigan B, Bartlett $H$, Clilverd A. Improving health and social functioning: perspectives of mental health service users. J Ment Health. 1997:6(6):613-20. https://doi.org/10.1080/09638239718473.

15. Penn DL, Sanna $\amalg$, Roberts DL. Social cognition in schizophrenia: an overview. Schizophr Bull. 2008;34(3):408-11. https://doi.org/10.1093/schbul/ sbn014.

16. Kessels RPC, Waanders-Oude Elferink M, van Tilborg I. Social cognition and social functioning in patients with amnestic mild cognitive impairment or Alzheimer's dementia. J Neuropsychol. 2020;15(2):186-203. 
17. Adenzato M, Todisco P, Ardito RB. Social cognition in anorexia nervosa: evidence of preserved theory of mind and impaired emotional functioning. PLoS One. 2012;7(8):e44414. https://doi.org/10.1371/journal.pone.0044414.

18. Schmidt SJ, Mueller DR, Roder V. Social cognition as a mediator variable between neurocognition and functional outcome in schizophrenia: empirical review and new results by structural equation modeling. Schizophr Bull. 2011;37(Suppl 2):S41-54. https://doi.org/10.1093/schbul/ sbr079.

19. Derntl B, Habel U. Deficits in social cognition: a marker for psychiatric disorders? Eur Arch Psychiatry Clin Neurosci. 2011;261(Suppl 2):S145-9. https://doi.org/10.1007/s00406-011-0244-0.

20. Deakin JB, Aitken MRF, Dowson JH, Robbins TW, Sahakian BJ. Diazepam produces disinhibitory cognitive effects in male volunteers. Psychopharmacology. 2004;173(1-2):88-97. https://doi.org/10.1007/s00213003-1695-4.

21. Ramaekers JG, Louwerens JW, Muntjewerff ND, Milius H, de Bie A, Rosenzweig P, et al. Psychomotor, cognitive, extrapyramidal, and affective functions of healthy volunteers during treatment with an atypical (amisulpride) and a classic (haloperidol) antipsychotic. J Clin Psychopharmacol. 1999;19(3):209-21. https://doi.org/10.1097/00004714-1 99906000-00003.

22. Veselinovic T, et al. Effects of antipsychotic treatment on cognition in healthy subjects. J Psychopharmacol. 2013;27(4):374-85. https://doi.org/1 $0.1177 / 0269881112466183$

23. Kleykamp BA, Griffiths RR, Mintzer MZ. Dose effects of triazolam and alcohol on cognitive performance in healthy volunteers. Exp Clin Psychopharmacol. 2010;18(1):1-16. https://doi.org/10.1037/a0018407.

24. Vigen $\mathrm{CL}$, et al. Cognitive effects of atypical antipsychotic medications in patients with Alzheimer's disease: outcomes from CATIE-AD. Am J Psychiatry. 2011;168(8):831-9. https://doi.org/10.1176/appi.ajp.2011.08121 844.

25. Keefe RS, et al. Neurocognitive effects of antipsychotic medications in patients with chronic schizophrenia in the CATIE trial. Arch Gen Psychiatry. 2007:64(6):633-47. https://doi.org/10.1001/archpsyc.64.6.633.

26. Weickert TW, Goldberg TE, Marenco S, Bigelow LB, Egan MF, Weinberger DR. Comparison of cognitive performances during a placebo period and an atypical antipsychotic treatment period in schizophrenia: critical examination of confounds. Neuropsychopharmacology. 2003;28(8):1491500. https://doi.org/10.1038/sj.npp.1300216.

27. Faber G, Smid HGOM, van Gool AR, Wiersma D, van den Bosch RJ. The effects of guided discontinuation of antipsychotics on neurocognition in first onset psychosis. Eur Psychiatry. 2012;27(4):275-80. https://doi.org/10.101 6/j.eurpsy.2011.02.003

28. Husa AP, Moilanen J, Murray GK, Marttila R, Haapea M, Rannikko I, et al. Lifetime antipsychotic medication and cognitive performance in schizophrenia at age 43 years in a general population birth cohort. Psychiatry Res. 2017;247:130-8. https://doi.org/10.1016/j.psychres.2016.10. 085.

29. Healy D, Farquhar G. Immediate effects of droperidol. Hum Psychopharmacol. 1998;13(2):113-20. https://doi.org/10.1002/(SICI)1099-1 077(199803)13:2<113:*AID-HUP958>3.0.CO:2-N

30. Moncrieff J. The myth of the magic antipsychotic. Ment Health Today. 2008; 22:18-9.

31. Kucharska-Pietura K, Mortimer A. Can antipsychotics improve social cognition in patients with schizophrenia? CNS Drugs. 2013;27(5):335-43. https://doi.org/10.1007/s40263-013-0047-0.

32. Teplan M. Fundamentals of EEG measurement. Meas Sci Rev. 2002;2(2):1-11.

33. Logothetis NK, Wandell BA. Interpreting the BOLD signal. Annu Rev Physiol. 2004;66(1):735-69. https://doi.org/10.1146/annurev.physiol.66.082602.092845.

34. Amodio DM, Bartholow BD, Ito TA. Tracking the dynamics of the social brain: ERP approaches for social cognitive and affective neuroscience. Soc Cogn Affect Neurosci. 2014;9(3):385-93. https://doi.org/10.1093/scan/nst177.

35. Redcay E, Moraczewski D. Social cognition in context: a naturalistic imaging approach. Neuroimage. 2020;216:116392. https://doi.org/10.1016/j.neuroima ge.2019.116392

36. Moher D, Liberati A, Tetzlaff J, Altman DG, PRISMA Group. Preferred reporting items for systematic reviews and meta-analyses: the PRISMA statement. J Clin Epidemiol. 2009;62(10):1006-12. https://doi.org/10.1016/j. jclinepi.2009.06.005.

37. Popay J, et al. Guidance on the conduct of narrative synthesis in systematic reviews. London: Institute for health research; 2006.
38. Nilsonne G, Tamm S, Golkar A, Sörman K, Howner K, Kristiansson M, et al. Effects of $25 \mathrm{mg}$ oxazepam on emotional mimicry and empathy for pain: a randomized controlled experiment. R Soc Open Sci. 2018;4(3). https://doi. org/10.1098/rsos.160607.

39. Pringle A, Warren M, Gottwald J, Cowen PJ, Harmer CJ. Cognitive mechanisms of diazepam administration: a healthy volunteer model of emotional processing. Psychopharmacology. 2016;233(12):2221-8. https:// doi.org/10.1007/s00213-016-4269-y.

40. Murphy SE, Downham C, Cowen PJ, Harmer CJ. Direct effects of diazepam on emotional processing in healthy volunteers. Psychopharmacology. 2008: 199(4):503-13. https://doi.org/10.1007/s00213-008-1082-2.

41. Zangara A, Blair RJ, Curran HV. A comparison of the effects of a betaadrenergic blocker and a benzodiazepine upon the recognition of human facial expressions. Psychopharmacology. 2002;163(1):36-41. https://doi.org/1 0.1007/s00213-002-1120-4

42. Blair RJ, Curran HV. Selective impairment in the recognition of anger induced by diazepam. Psychopharmacology. 1999;147(3):335-8. https://doi. org/10.1007/s002130051177.

43. Del-Ben $C M$, et al. Effects of diazepam on BOLD activation during the processing of aversive faces. J Psychopharmacol. 2012;26(4):443-51. https:// doi.org/10.1177/0269881110389092.

44. Coupland NJ, Singh AJ, Sustrik RA, Ting P, Blair R. Effects of diazepam on facial emotion recognition. J Psychiatry Neurosci. 2003;28(6):452-63.

45. Olofsson JK, Gospic K, Petrovic P, Ingvar M, Wiens S. Effects of oxazepam on affective perception, recognition, and event-related potentials. Psychopharmacology. 2011;215(2):301-9. https://doi.org/10.1007/s00213-01 0-2141-z.

46. Richter A, Grimm S, Northoff G. Lorazepam modulates orbitofrontal signal changes during emotional processing in catatonia. Hum Psychopharmacol. 2010:25(1):55-62. https://doi.org/10.1002/hup.1084.

47. Lawrence AD, Calder AJ, McGowan SW, Grasby PM. Selective disruption of the recognition of facial expressions of anger. Neuroreport. 2002;13(6):8814. https://doi.org/10.1097/00001756-200205070-00029.

48. Rock PL, Goodwin GM, Wulff K, McTavish SFB, Harmer CJ. Effects of shortterm quetiapine treatment on emotional processing, sleep and circadian rhythms. J Psychopharmacol. 2016;30(3):273-82. https://doi.org/10.1177/02 69881115626336.

49. Mizrahi R, Addington J, Remington G, Kapur S. Attribution style as a factor in psychosis and symptom resolution. Schizophr Res. 2008;104(1-3):220-7. https://doi.org/10.1016/j.schres.2008.05.003.

50. Gaebel W, Wolwer W. Facial expression and emotional face recognition in schizophrenia and depression. Eur Arch Psychiatry Clin Neurosci. 1992; 242(1):46-52. https://doi.org/10.1007/BF02190342.

51. Olivier MR, Killian S, Chiliza B, Asmal L, Schoeman R, Oosthuizen PP, et al. Cognitive performance during the first year of treatment in first-episode schizophrenia: a case-control study. Psychol Med. 2015;45(13):2873-83. https://doi.org/10.1017/S0033291715000860.

52. Zhou Z, Zhu Y, Wang J, Zhu H. Risperidone improves interpersonal perception and executive function in patients with schizophrenia. Neuropsychiatr Dis Treat. 2017;13:101-7. https://doi.org/10.2147/NDT.S12 0843

53. Lewis SF, Garver DL. Treatment and diagnostic subtype in facial affect recognition in schizophrenia. J Psychiatr Res. 1995;29(1):5-11. https://doi. org/10.1016/0022-3956(94)00033-N.

54. Herbener ES, Hill SK, Marvin RW, Sweeney JA. Effects of antipsychotic treatment on emotion perception deficits in first-episode schizophrenia. Am J Psychiatry. 2005;162(9):1746-8. https://doi.org/10.1176/appi.ajp.162.9.1746.

55. Roberts DL, Penn DL, Corrigan P, Lipkovich I, Kinon B, Black RA. Antipsychotic medication and social cue recognition in chronic schizophrenia. Psychiatry Res. 2010;178(1):46-50. https://doi.org/10.1016/j. psychres.2010.04.006.

56. Mizrahi R, et al. The effect of antipsychotic treatment on theory of mind Psychol Med. 2007;37(4):595-601. https://doi.org/10.1017/S0033291 706009342

57. Kucharska-Pietura K, Mortimer A, Tylec A, Czernikiewicz A. Social cognition and visual perception in schizophrenia inpatients treated with first-and second-generation antipsychotic drugs. Clin Schizophr Relat Psychoses. 2012;6(1):14-20. https://doi.org/10.3371/CSRP.6.1.2.

58. Wolwer W, et al. Facial affect recognition in the course of schizophrenia. Eur Arch Psychiatry Clin Neurosci. 1996;246(3):165-70. https://doi.org/10.1007/ BF02189118. 
59. Gultekin G, Yuksek E, Kalelioglu T, Bas A, Ocek Bas T, Duran A. Differential effects of clozapine and risperidone on facial emotion recognition ability in patients with treatment-resistant schizophrenia. Psychiatry Clin Psychopharmacol. 2017;27(1):19-23. https://doi.org/10.1080/24750573.201 7.1293242.

60. Maat A, Cahn W, Gijsman HJ, Hovens JE, Kahn RS, Aleman A. Open, randomized trial of the effects of aripiprazole versus risperidone on social cognition in schizophrenia. Eur Neuropsychopharmacol. 2014;24(4):575-84. https://doi.org/10.1016/j.euroneuro.2013.12.009.

61. Behere RV, Venkatasubramanian G, Arasappa R, Reddy N, Gangadhar BN. Effect of risperidone on emotion recognition deficits in antipsychotic-naive schizophrenia: a short-term follow-up study. Schizophr Res. 2009;113(1):726. https://doi.org/10.1016/j.schres.2009.05.026.

62. Harvey PD, et al. Improvement in social competence with short-term atypical antipsychotic treatment: a randomized, double-blind comparison of quetiapine versus risperidone for social competence, social cognition, and neuropsychological functioning. Am J Psychiatry. 2006;163(11):1918-25. https://doi.org/10.1176/ajp.2006.163.11.1918.

63. Shi $C$, Yao Shuqiao S, Xu Y, Shi J, Xu X, Zhang C, et al. Improvement in social and cognitive functioning associated with paliperidone extendedrelease treatment in patients with schizophrenia: a 24-week, single arm, open-label study. Neuropsychiatr Dis Treat. 2016;12:2095-104. https://doi. org/10.2147/NDT.S112542.

64. Penn DL, Keefe RSE, Davis SM, Meyer PS, Perkins DO, Losardo D, et al. The effects of antipsychotic medications on emotion perception in patients with chronic schizophrenia in the CATIE trial. Schizophr Res. 2009;115(1):17-23. https://doi.org/10.1016/j.schres.2009.08.016.

65. Sergi MJ, et al. Social cognition [corrected] and neurocognition: effects of risperidone, olanzapine, and haloperidol. Am J Psychiatry. 2007;164(10): 1585-92. https://doi.org/10.1176/appi.ajp.2007.06091515.

66. Kee KS, Kern RS, Marshall BD Jr, Green MF. Risperidone versus haloperidol for perception of emotion in treatment-resistant schizophrenia: preliminary findings. Schizophr Res. 1998;31(2-3):159-65. https://doi.org/10.1016/S09209964(98)00026-7.

67. Koshikawa Y, Takekita Y, Kato M, Sakai S, Onohara A, Sunada N, et al. The comparative effects of risperidone long-acting injection and Paliperidone palmitate on social functioning in schizophrenia: a 6-month, open-label, Randomized Controlled Pilot Trial. Neuropsychobiology. 2016;73(1):35-42. https://doi.org/10.1159/000442209.

68. Daros AR, Ruocco AC, Reilly JL, Harris MSH, Sweeney JA. Facial emotion recognition in first-episode schizophrenia and bipolar disorder with psychosis. Schizophr Res. 2014;153(1-3):32-7. https://doi.org/10.1016/j. schres.2014.01.009.

69. Savina I, Beninger RJ. Schizophrenic patients treated with clozapine or olanzapine perform better on theory of mind tasks than those treated with risperidone or typical antipsychotic medications. Schizophr Res. 2007;94(13):128-38. https://doi.org/10.1016/j.schres.2007.04.010.

70. Fakra E, Salgado-Pineda P, Besnier N, Azorin JM, Blin O. Risperidone versus haloperidol for facial affect recognition in schizophrenia: findings from a randomised study. World J Biol Psychiatry. 2009;10(4 Pt 3):719-28. https:// doi.org/10.1080/15622970701432536.

71. Labuschagne I, Jones R, Callaghan J, Whitehead D, Dumas EM, Say MJ, et al. Emotional face recognition deficits and medication effects in pre-manifest through stage-II Huntington's disease. Psychiatry Res. 2013;207(1-2):118-26. https://doi.org/10.1016/j.psychres.2012.09.022.

72. Kucharska-Pietura K, Tylec A, Czernikiewicz A, Mortimer A. Attentional and emotional functioning in schizophrenia patients treated with conventional and atypical antipsychotic drugs. Med Sci Monit. 2012;18(1):CR44-9. https:// doi.org/10.12659/msm.882202.

73. Sumiyoshi T, Higuchi $Y$, Itoh T, Matsui M, Arai H, Suzuki M, et al. Effect of perospirone on P300 electrophysiological activity and social cognition in schizophrenia: a three-dimensional analysis with sloreta. Psychiatry Res. 2009;172(3):180-3. https://doi.org/10.1016/j.pscychresns.2008.07.005.

74. Takahashi H, Yahata N, Koeda M, Takano A, Asai K, Suhara T, et al. Effects of dopaminergic and serotonergic manipulation on emotional processing: a pharmacological fMRI study. Neuroimage. 2005;27(4):991-1001. https://doi. org/10.1016/j.neuroimage.2005.05.039.

75. Franken $\mathrm{IH}$, Nijs I, Pepplinkhuizen L. Effects of dopaminergic modulation on electrophysiological brain response to affective stimuli. Psychopharmacology. 2008;195(4):537-46. https://doi.org/10.1007/s00213007-0941-6.
76. Wesnes K, Pincock C. Practice effects on cognitive tasks: a major problem? Lancet Neurol. 2002;1(8):473. https://doi.org/10.1016/S1474-4422(02)00236-3.

77. Foeckler, P., V. Henning, and J. Reichelt, Mendeley. 2008: London, UK

78. Downs SH, Black N. The feasibility of creating a checklist for the assessment of the methodological quality both of randomised and non-randomised studies of health care interventions. J Epidemiol Community Health. 1998; 52(6):377-84. https://doi.org/10.1136/jech.52.6.377.

79. Trac MH, McArthur E, Jandoc R, Dixon SN, Nash DM, Hackam DG, et al. Macrolide antibiotics and the risk of ventricular arrhythmia in older adults. CMAJ. 2016;188(7):E120-9. https://doi.org/10.1503/cmaj.150901.

80. McHugh ML. Interrater reliability: the kappa statistic. Biochem Med (Zagreb). 2012;22(3):276-82. https://doi.org/10.11613/BM.2012.031.

81. Zurowska $\mathrm{N}$, et al. Recognition of emotional facial expressions in benzodiazepine dependence and detoxification. Cogn Neuropsychiatry. 2018;23(2):74-87. https://doi.org/10.1080/13546805.2018.1426448.

82. Paulus MP, Feinstein JS, Castillo G, Simmons AN, Stein MB. Dose-dependent decrease of activation in bilateral amygdala and insula by lorazepam during emotion processing. Arch Gen Psychiatry. 2005;62(3):282-8. https://doi.org/1 0.1001/archpsyc.62.3.282

83. Fujii DE, Wylie AM, Nathan JH. Neurocognition and long-term prediction of quality of life in outpatients with severe and persistent mental illness. Schizophr Res. 2004;69(1):67-73. https://doi.org/10.1016/S0920-9964(03 )00122-1.

84. Hudson C, Chan J. Individuals with intellectual disability and mental illness: a literature review. Aust J Soc Issues. 2016;37(1):31-49. https://doi.org/10.1 002/j.1839-4655.2002.tb01109.x.

85. Banks SJ, Eddy KT, Angstadt M, Nathan PJ, Phan KL. Amygdala-frontal connectivity during emotion regulation. Soc Cogn Affect Neurosci. 2007; 2(4):303-12. https://doi.org/10.1093/scan/nsm029.

86. Anderson KE, Marder KS. An overview of psychiatric symptoms in Huntington's disease. Curr Psychiatry Rep. 2001;3(5):379-88. https://doi.org/1 0.1007/s11920-996-0030-2.

87. McKee SA. Concurrent substance use disorders and mental illness: bridging the gap between research and treatment. Can Psychol. 2017;58(1):50-7. https://doi.org/10.1037/cap0000093.

88. Choi JH, Kim JH, Lee J, Green MF. Social Cognition training for individuals with schizophrenia: a review of targeted interventions. Clin Psychopharmacol Neurosci. 2009;7(2):29-38.

89. Kurtz MM, Gagen E, Rocha NBF, Machado S, Penn DL. Comprehensive treatments for social cognitive deficits in schizophrenia: a critical review and effect-size analysis of controlled studies. Clin Psychol Rev. 2016;43:80-9. https://doi.org/10.1016/j.cpr.2015.09.003.

\section{Publisher's Note}

Springer Nature remains neutral with regard to jurisdictional claims in published maps and institutional affiliations.

\section{Ready to submit your research? Choose BMC and benefit from:}

- fast, convenient online submission

- thorough peer review by experienced researchers in your field

- rapid publication on acceptance

- support for research data, including large and complex data types

- gold Open Access which fosters wider collaboration and increased citations

- maximum visibility for your research: over $100 \mathrm{M}$ website views per year

At BMC, research is always in progress.

Learn more biomedcentral.com/submissions 